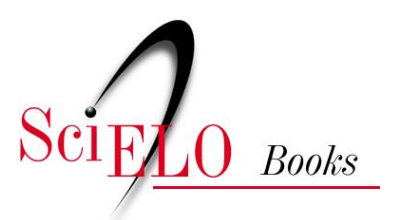

Fiockuz

ipea

\title{
O papel federal no sistema de saúde brasileiro
}

\author{
Cristiani Vieira Machado
}

\section{SciELO Books / SciELO Livros / SciELO Libros}

MACHADO, CV. O papel federal no sistema de saúde brasileiro. In FUNDAÇÃO OSWALDO CRUZ. A saúde no Brasil em 2030 - prospecção estratégica do sistema de saúde brasileiro: organização e gestão do sistema de saúde [online]. Rio de Janeiro: Fiocruz/Ipea/Ministério da Saúde/Secretaria de Assuntos Estratégicos da Presidência da República, 2013. Vol. 3. 35-70 pp. ISBN 978-85-8110-017-3. Available from SciELO Books <http://books.scielo.org $>$.

\section{(2)(1)(2)}

All the contents of this chapter, except where otherwise noted, is licensed under a Creative Commons Attribution-Non Commercial-ShareAlike 3.0 Unported.

Todo o conteúdo deste capítulo, exceto quando houver ressalva, é publicado sob a licença Creative Commons Atribuição Uso Não Comercial - Partilha nos Mesmos Termos 3.0 Não adaptada.

Todo el contenido de este capítulo, excepto donde se indique lo contrario, está bajo licencia de la licencia Creative Commons Reconocimento-NoComercial-CompartirIgual 3.0 Unported. 
O Papel Federal no Sistema de Saúde Brasileiro 


\title{
O PAPEL FEDERAL NO SISTEMA DE SAÚDE BRASILEIRO ${ }^{1}$
}

\author{
Cristiani Vieira Machado
}

A federação brasileira historicamente apresenta como um traço constitutivo a presença de um Executivo Federal forte, na sua relação com os demais Poderes de Estado e entes federativos. Nos últimos vinte anos, apesar dos processos de reforma do Estado e de descentralização, esse peso federal foi reafirmado, ainda que em novas bases, o que se expressou em várias áreas das políticas sociais (ALMEIDA, 2007, ARRETCHE, 2009).

No que diz respeito à saúde, o projeto da reforma sanitária brasileira que levou à instituição do Sistema Único de Saúde (SUS) pela Constituição de 1988 pressupunha profundas mudanças no papel do Estado na saúde nas três esferas de governo. Em 1990, a promulgação da Lei Orgânica da Saúde e a incorporação do Instituto Nacional de Assistência Médica da Previdência Social (INAMPS) ao Ministério da Saúde delimitaram as novas regras institucionais para a atuação da autoridade sanitária nacional. A instituição do SUS, a unificação do comando sobre a política nacional e a descentralização político-administrativa trouxeram repercussões para o papel federal na saúde, exigindo mudanças na estrutura, campos, funções e lógica de atuação do Ministério da Saúde.

No entanto, as transformações na atuação do Ministério nos anos subsequentes não decorreram apenas da agenda de construção do SUS. Elas também foram condicionadas por outras variáveis histórico-estruturais, institucionais e político-conjunturais, relacionadas tanto a movimentos gerais de mudanças no Estado brasileiro como às singularidades da política de saúde. Assim, características históricoestruturais do sistema de saúde brasileiro (como o forte peso do setor privado) e processos de reforma do Estado de inspiração neoliberal (particularmente nos anos 1990) impuseram limites à reconfiguração de um papel positivo para a esfera federal na consolidação do SUS.

1 A elaboração deste texto se apoiou nos resultados de pesquisas que vem sendo coordenadas pela autora, com o apoio financeiro do CNPq e da FAPERJ. Parte do item 3 foi publicada anteriormente em Machado (2012). Os dois capítulos, no entanto, apresentam muitas diferenças. 
Nesse sentido, cabe levantar algumas questões relevantes: a atuação do Estado na saúde no âmbito nacional tem contribuído para a consolidação de um sistema público e universal de saúde, baseado no reconhecimento da saúde como direito de cidadania? Quais seriam as finalidades da atuação federal no setor no contexto atual, considerando as características do país e os princípios constitucionais relativos à Seguridade Social e ao SUS? Como fortalecer a capacidade institucional do Estado na esfera federal no sentido de alcançar essas finalidades?

Este texto aborda o papel da esfera federal na condução da política nacional e na gestão do sistema de saúde no Brasil, com o propósito de identificar os desafios para a reconfiguração estratégica da atuação do Executivo Federal. A abordagem adotada privilegia a compreensão do contexto atual da gestão federal da política de saúde à luz de variáveis histórico-estruturais e políticas, visando levantar aspectos críticos para o fortalecimento da capacidade institucional do Estado na garantia da saúde como direito de cidadania no país, nas próximas duas décadas.

Além desta introdução, o capítulo compreende quatro outros itens. O próximo item discute quais seriam as finalidades da atuação federal na saúde, à luz das especificidades da federação e do sistema de saúde brasileiro. O terceiro item explora as mudanças na estrutura e nos campos de atuação do Estado no âmbito federal. O quarto aborda o modelo de intervenção federal na saúde, considerando as funções estatais de planejamento, financiamento, regulação e execução direta de serviços. O quinto discute brevemente o tema da articulação da política de saúde com outras políticas públicas. Por fim, na seção final são discutidos os principais desafios para a reconfiguração do papel federal na saúde.

\section{1 | FINALIDADES DA ATUAÇÃO FEDERAL NA SAÚdE}

A princípio, identificam-se ao menos quatro finalidades estratégicas da atuação federal na política de saúde, que deveriam nortear a atuação do Ministério da Saúde no Brasil. A primeira delas é a luta pela inserção da saúde em um novo modelo de desenvolvimento econômico e social, orientado pela ampliação do bem-estar do conjunto da população. Isso requer a conformação de um sistema de proteção social abrangente, baseado em valores de igualdade e de direitos sociais de cidadania amplos, que articule políticas universais sólidas e políticas de redução da pobreza e das desigualdades. Mais do que isso, requer que a proteção social tenha centralidade no modelo de desenvolvimento, de forma que a lógica da redistribuição se imponha sobre a do crescimento econômico (e não seja apenas condicionada ou subordinada ao crescimento).

Embora as regras formalizadas na Constituição de 1988 tenham sido inspiradas pelos Welfare States avançados, a inserção e a configuração atual do sistema 
de proteção social brasileiro - e do sistema de saúde - expressam contradições expressivas que o distanciam da concepção de universalismo abrangente. Situar a condução da política nacional de saúde nessa perspectiva pressupõe a adoção de estratégias voltadas para a efetivação do direito à saúde e a articulação virtuosa da política setorial com outras políticas econômicas e sociais, o que envolveria rupturas mais drásticas com o status quo e conflitos redistributivos. Ainda que boa parte das decisões políticas relevantes para viabilizar tais transformações esteja fora da governabilidade do Ministério da Saúde, cabe à autoridade sanitária nacional a defesa permanente de tal projeto como condição sine qua non para a concretização da saúde como direito universal de cidadania.

A segunda finalidade concerne à garantia de condições favoráveis para a melhoria das condições de saúde da população em todo o território nacional, considerando a situação atual e o cenário de mudanças demográficas e epidemiológicas para as próximas duas décadas. Isso exige o enfrentamento dos determinantes sociais da doença, por meio de políticas públicas articuladas (de emprego, saúde, saneamento, educação, previdência, assistência social). Requer ainda políticas nacionais de saúde voltadas para o fortalecimento da promoção, prevenção, tratamento e reabilitação dos mais diversos agravos, junto a variados grupos populacionais. Ainda que a execução de muitas dessas políticas possa estar sob responsabilidade estadual ou municipal, cabe à esfera federal assegurar condições adequadas para sua expansão e desenvolvimento, em termos políticos, financeiros, tecnológicos e institucionais. Por exemplo, o envelhecimento da população exigirá a intensificação das políticas de promoção da saúde, mas também o aumento de oferta de serviços para a atenção às doenças crônicodegenerativas e neoplasias, incluindo tecnologias de alto custo e leitos hospitalares especializados. Tal ampliação requer planejamento, investimentos e fortalecimento da capacidade de regulação federal para que a incorporação tecnológica e a expansão de serviços se dêem de acordo com as necessidades de atenção à saúde da população e os princípios do SUS de universalidade e integralidade (e não sob a lógica do consumo e os interesses dos mercados).

A terceira finalidade, relacionada às anteriores, diz respeito à busca de redução das desigualdades em saúde em suas várias dimensões — financiamento, acesso, uso, qualidade, situação de saúde - no âmbito territorial e entre grupos sociais, dadas as características da sociedade e do sistema de saúde brasileiro. Sabe-se que as marcantes desigualdades em saúde refletem determinações histórico-estruturais, políticas e sociais amplas e que também expressam a trajetória da política de saúde brasileira anterior ao SUS.

Ainda que nos últimos vinte anos algumas iniciativas tenham sido adotadas para reduzi-las (como mudanças incrementais nos mecanismos de financiamento), persistem no sistema de saúde engrenagens que reproduzem desigualdades. Alguns exemplos são: o peso predominante da oferta na determinação 
do volume de financiamento federal, particularmente no que se refere aos serviços de média e alta complexidade; a proliferação de programas federais fortemente orientados pela adesão das esferas subnacionais ou dos prestadores; a frágil incorporação da dimensão territorial na formulação e implantação das políticas de saúde; a fragilidade da regulação federal sobre os segmentos privados (prestadores ao SUS, planos privados, indústrias da saúde), que não tem favorecido a superação das distorções nas relações público-privadas em saúde. Direcionar a política nacional para a redução das desigualdades requer planejamento de longo prazo, realização de investimentos federais expressivos associados a políticas regionais e a mudança dos propósitos e do modelo de regulação estatal sobre os agentes privados.

A quarta finalidade de atuação do Ministério da Saúde concerne à coordenação federativa da política de saúde. As características da federação brasileira, o peso importante do Executivo federal e as transformações das últimas décadas relacionadas à descentralização político-administrativa impõem novos desafios à articulação entre as esferas federal, estadual e municipal para consolidar políticas de saúde coerentes com os princípios do SUS e os valores de cidadania nacional.

A discussão empreendida nos próximos itens parte do reconhecimento dessas quatro grandes finalidades de atuação federal na saúde.

\section{2 | ESTRUTURA E CAMPOS DE ATUAÇÃO FEDERAL NA SAÚDE}

No Brasil, as regras constitucionais e legais definem que a responsabilidade pela condução da política de saúde no âmbito federal cabe ao Ministério da Saúde, que é a autoridade sanitária nacional e o gestor federal do SUS. A formulação de políticas nacionais, no entanto, deve ser compartilhada com outros atores sociais nos canais institucionais formalmente definidos, em consonância com as diretrizes relativas à coordenação federativa e à participação social na saúde.

O Ministério da Saúde brasileiro foi criado em 1953, a partir do desmembramento do antigo Ministério da Educação e Saúde Pública (MESP)². No entanto, naquela época o ministério era responsável somente pelas ações de saúde pública, já que a assistência médica previdenciária estava sob comando dos Institutos de Aposentadorias e Pensões, ligados ao Ministério do Trabalho e Previdência Social.

Somente após a instituição do SUS e com a incorporação do Instituto Nacional de Assistência Médica da Previdência Social (INAMPS) ao Ministério da Saúde em 1990 é que ocorre a unificação institucional do comando sobre a política nacional

2 Para uma análise da trajetória do MESP, ver Fonseca (2007) e para uma análise da criação do Ministério da Saúde em 1953, consultar Hamilton e Fonseca (2003). 
de saúde. Nas duas décadas subsequentes, o Ministério passou por transformações institucionais importantes, por meio da incorporação, criação ou extinção de órgãos e entidades, influenciadas por reformas gerais no Estado ou pelo contexto específico das mudanças nas políticas e nos campos de ação estatal na saúde.

A Figura 1 ilustra as principais mudanças na estrutura do Ministério da Saúde no período de 1990 a 2010.

Figura 01. Principais mudanças na estrutura administrativa do Ministério da Saúde de 1990 a 2010

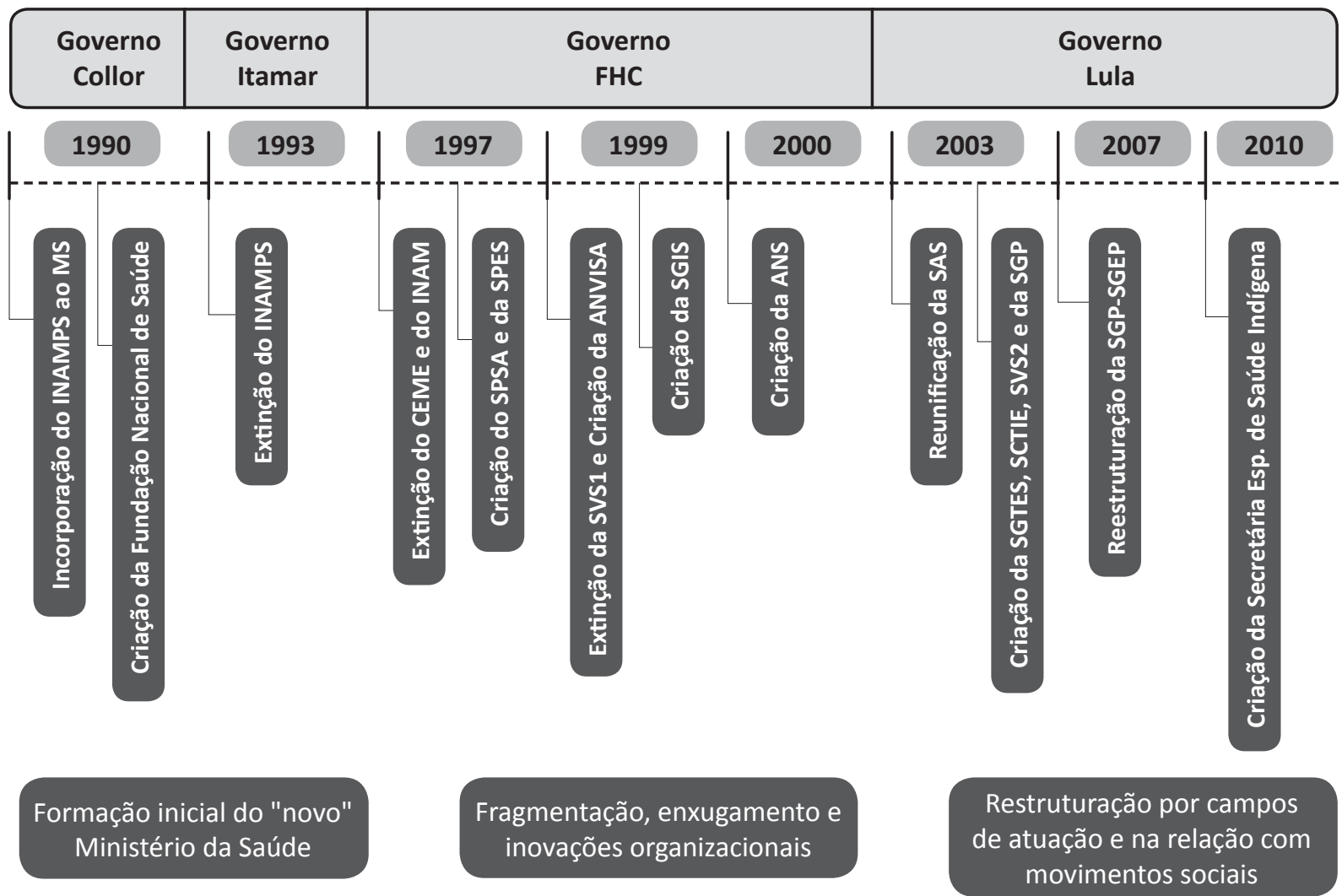

Fonte: Elaboração própria.

Nota: INAMPS — Instituto Nacional de Assistência Médica da Previdência Social; MS — Ministério da Saúde; CEME — Central de Medicamentos; INAN — Instituto Nacional de Alimentação e Nutrição; SPSA — Secretaria de Políticas de Saúde e de Avaliação; SPES — Secretaria de Projetos Especiais de Saúde; SVS1 — Secretaria de Vigilância Sanitária; ANVISA — Agência Nacional de Vigilância Sanitária; SGIS - Secretaria de Gestão de Investimentos em Saúde; ANS — Agência Nacional de Saúde Suplementar; SAS — Secretaria de Atenção à Saúde; SGTES — Secretaria de Gestão do Trabalho e da Educação na Saúde; SVS2 — Secretaria de Vigilância em Saúde; SGP — Secretaria de Gestão Participativa; SGEP — Secretaria de Gestão Estratégica e Participativa.

Observam-se ao menos três diferentes momentos no que concerne à trajetória da estrutura administrativa do Ministério da Saúde nesse período de vinte anos. No início dos anos 1990, predominam as mudanças relativas à unificação de estruturas com vistas à formação da nova autoridade sanitária nacional, para dar conta do novo papel federal na saúde. Destacam-se a incorporação do INAMPS ao 
Ministério ${ }^{3}$ e a conformação da Fundação Nacional de Saúde, a partir da junção da Fundação Serviços de Saúde Pública (FSESP) e da Superintendência de Campanhas de Saúde Pública (SUCAM).

Um segundo momento relevante ocorre durante o Governo FHC, entre 1997 e 2000, caracterizado por fragmentação da estrutura e por mudanças influenciadas pelo contexto de reforma administrativa federal. Particularmente os anos de 1997-1998 são marcados pelo enxugamento da estrutura por meio da extinção de entidades federais como a Central de Medicamentos (CEME) e o Instituto Nacional de Alimentação e Nutrição (INAN), em um contexto de aceleração da descentralização de políticas (no caso, de assistência farmacêutica e combate a problemas nutricionais). Ainda expressando influências do contexto de reforma do Estado, no período 19992000 ocorrem inovações organizacionais relevantes, como a criação das agências reguladoras da saúde. A criação dessas entidades de certa forma sinaliza um movimento de expansão das atividades regulatórias nas áreas de vigilância sanitária e assistência médica suplementar, embora fora do âmbito da administração direta.

Um terceiro momento bastante distinto se configura durante o Governo Lula. Em 2003 ocorre uma mudança importante na estrutura do Ministério da Saúde, destacando-se: (a) a reunificação da Secretaria de Atenção à Saúde (a partir da unificação das secretarias de Políticas e de Assistência à Saúde); (b) a criação das secretarias de Gestão do Trabalho e da Educação na Saúde (SGTES) e de Ciência, Tecnologia e Insumos Estratégicos (SCTIE), que representa uma iniciativa de fortalecimento de campos nos quais havia fragilidades de atuação federal; (c) a criação da Secretária de Vigilância em Saúde, que incorpora ações de vigilância e controle de doenças específicas antes sob responsabilidade da Fundação Nacional de Saúde (FUNASA); (d) a criação da Secretaria de Gestão Participativa, que em 2007 se transforma em Secretaria de Gestão Estratégica e Participativa, tendo por objetivo de fortalecer a gestão participativa no SUS e aumentar o diálogo com movimentos sociais. Ressalte-se ainda a criação no segundo semestre de 2010 da Secretaria Especial de Saúde Indígena, o que veio a reduzir ainda mais as atribuições da FUNASA.

A estrutura atual do Ministério da Saúde é apresentada na Figura 2.

3 O decreto de incorporação do INAMPS ao Ministério da Saúde foi assinado nos últimos dias do Governo Sarney. Já a conformação da Fundação Nacional de Saúde foi regulamentada no Governo Collor. Para maiores detalhes, ver Machado (2007b). 


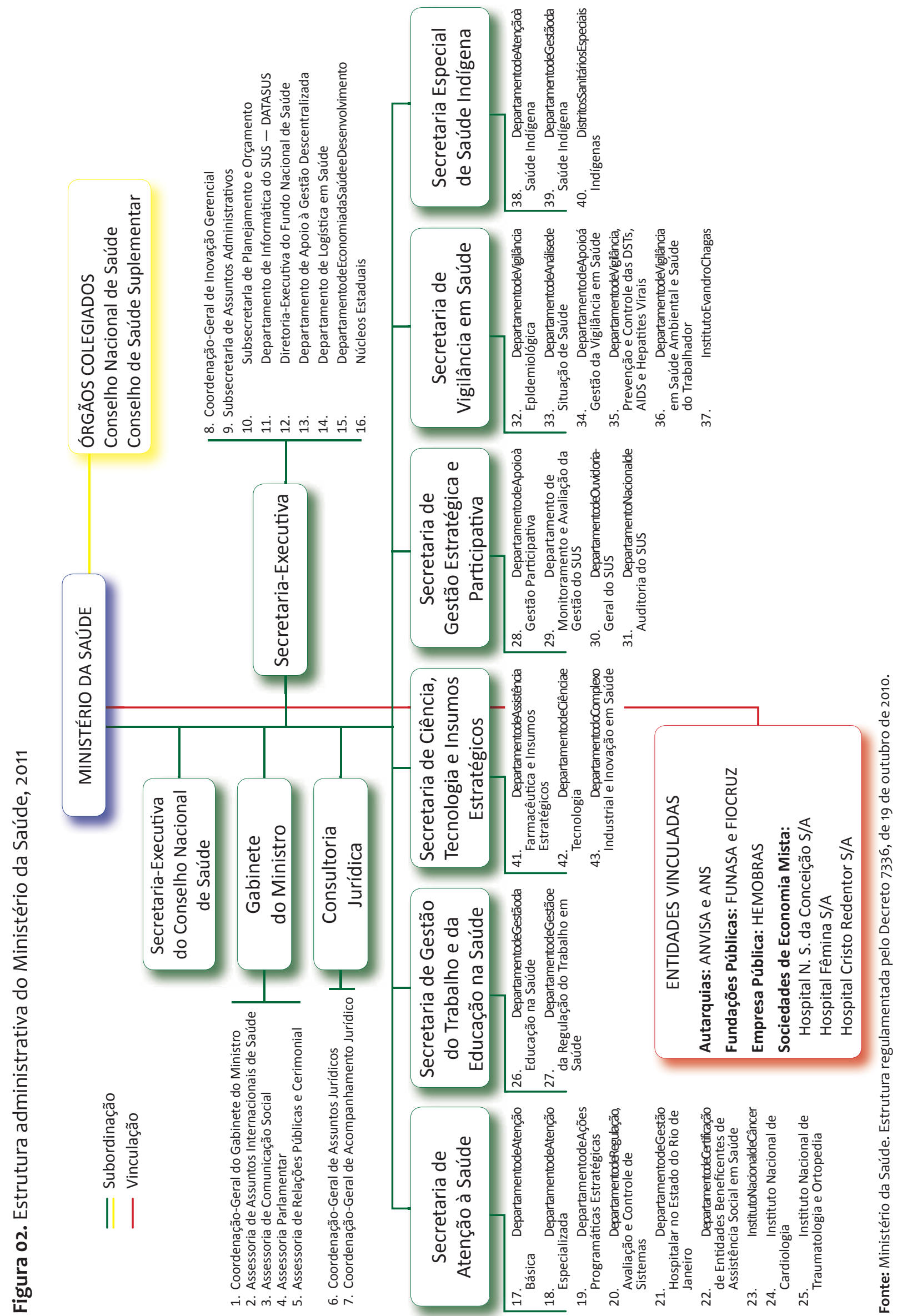


Essa estrutura atual compreende, portanto, quatro secretarias de primeiro escalão voltadas para campos específicos de atuação do Estado na saúde: atenção à saúde, vigilância em saúde, gestão do trabalho e da educação na saúde e ciência, tecnologia e insumos estratégicos. Além disso, abrange duas outras secretarias, voltadas respectivamente para fortalecimento da gestão participativa/articulação com movimentos sociais e auditoria (SGEP) e a organização da atenção para uma população específica (indígena). Ressalte-se ainda a existência de entidades vinculadas que são: duas fundações públicas, com atribuições muito distintas (Fundação Nacional de Saúde e Fundação Oswaldo Cruz); duas agências reguladoras constituídas sob a forma de autarquias, que atuam em campos bastante diferentes (Agência Nacional de Vigilância Sanitária - ANVISA — e Agência Nacional de Saúde Suplementar — ANS); uma empresa pública, que ainda não está em pleno funcionamento (Hemobrás); e, como sociedades de economia mista, as unidades que compõem o Grupo Hospitalar Conceição, no Rio Grande do Sul. Cabe ainda assinalar que existem hospitais federais integrantes da administração direta vinculados à Secretaria de Atenção à Saúde.

De certa forma, a atual estrutura parece mais coerente com a perspectiva dos campos de atuação do Estado na saúde. No entanto, persistem problemas de fragmentação interna, sobreposição de atribuições, limites na coordenação e convivência de lógicas distintas de formulação e gestão das políticas de saúde.

É importante reconhecer que a definição de campos de atuação do Estado na saúde não é simples nem consensual, envolvendo embates teórico-conceituais e políticos. Vários tipos de abordagens e delimitações são possíveis, mas sempre haverá sobreposições e interdependência entre os campos. Isso porque tais divisões não são estanques, mas sim fruto de processos históricos, disputas e construções políticas. Assim, a delimitação (em algum grau arbitrária) dos campos de atuação do Estado na esfera federal pode ter diferentes pontos de partida ou tipos de ênfase: (a) elementos históricos e teórico-conceituais sobre o campo da saúde/ da atenção à saúde; (b) o marco constitucional-legal e outras definições normativas; (c) a estrutura administrativa do Ministério da Saúde; (d) a observação empírica da atuação do Ministério em um dado período.

Em uma perspectiva didática, a atuação do Estado na saúde pode ser ainda compreendida em dois planos de análise, com implicações para o papel do Ministério da Saúde. O primeiro é o plano dos campos típicos de atenção à saúde (assistência, vigilâncias), que compreende as áreas e as atividades mais diretamente voltadas para o atendimento das necessidades sociais de saúde, em geral sob responsabilidade principal da autoridade sanitária da saúde.

Um segundo plano de análise mais abrangente engloba, além dos campos típicos da atenção à saúde, outros campos de atuação do Estado na saúde (desenvolvimento científico e tecnológico em saúde, a política industrial para o setor 
saúde, a provisão de insumos, a formação de recursos humanos e a regulação dos vários mercados em saúde), estratégicos em uma política pública voltada para a garantia da saúde como direito social de cidadania. O desenvolvimento de políticas nessas áreas em geral extrapola o âmbito de ação exclusiva da autoridade sanitária nacional. No entanto, a atuação combinada do Ministério da Saúde nos vários campos é importante para assegurar a orientação dessas políticas para o atendimento das necessidades sociais de saúde, configurando uma concepção ampliada sobre a política de saúde, em sua dimensão social, econômica e de poder.

É nesse sentido que pode ser compreendido o esforço de estruturação de algumas novas secretarias no Ministério em 2003, visando ampliar a ação do gestor federal do SUS em campos estratégicos sobre os quais a sua governabilidade e intervenção eram até então bastante limitadas.

Neste texto, a análise sobre os campos de atuação federal na saúde privilegia as regras formais e a observação empírica da atuação federal, mas também considera outras variáveis, como os elementos históricos e a especificidade do papel federal na saúde. O Quadro 1 resume as principais características dos campos de atuação federal na saúde no período de implantação do SUS, visando identificar as principais áreas de atividade e desafios de atuação do gestor federal em cada um. 


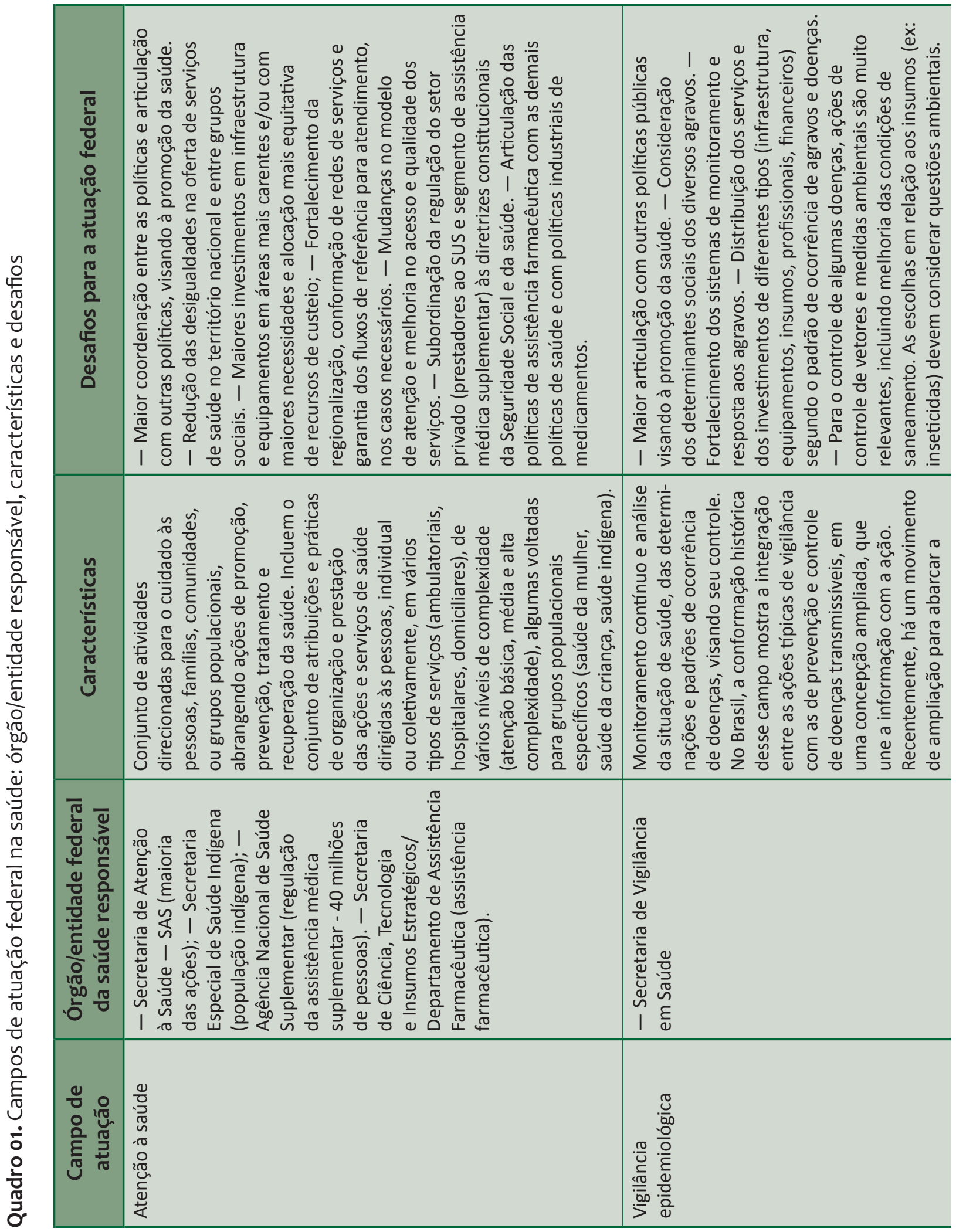




\begin{tabular}{|c|c|c|}
\hline 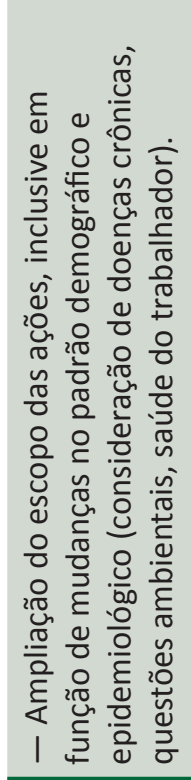 & 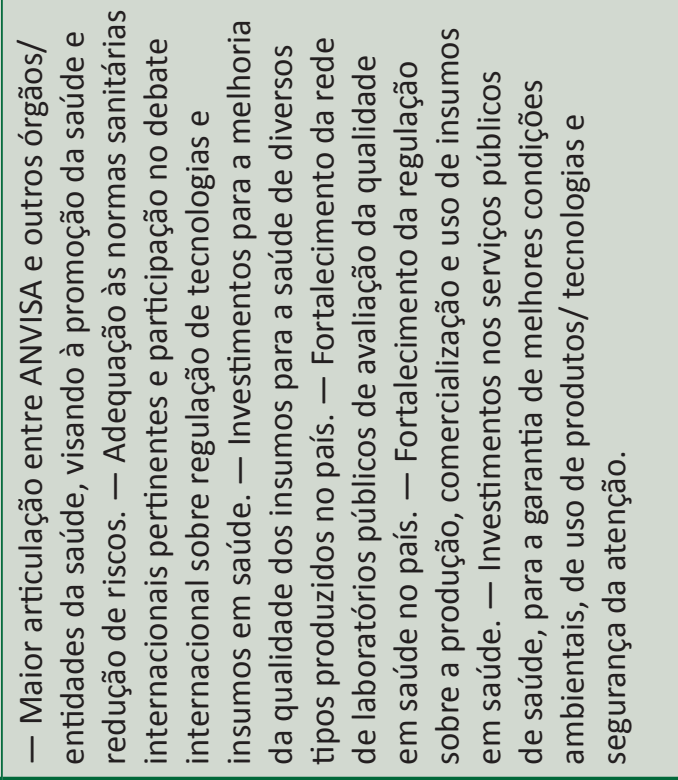 & 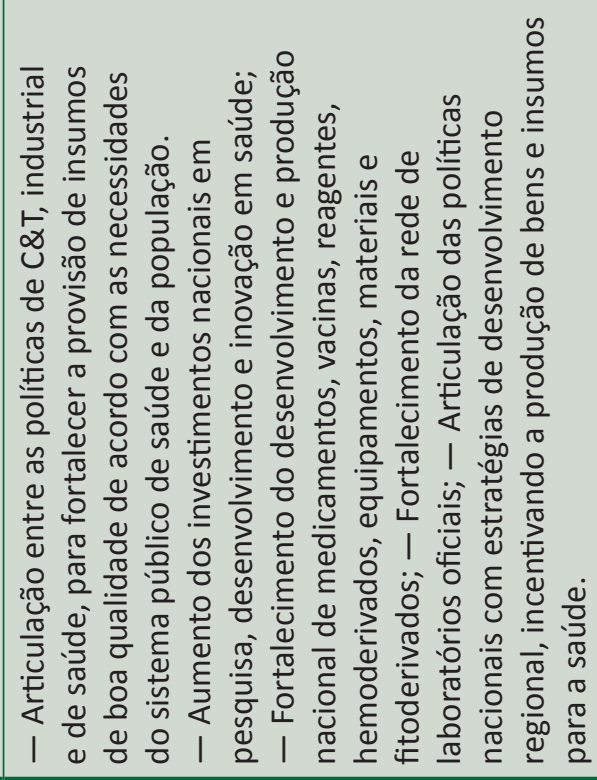 \\
\hline \multirow[t]{3}{*}{ 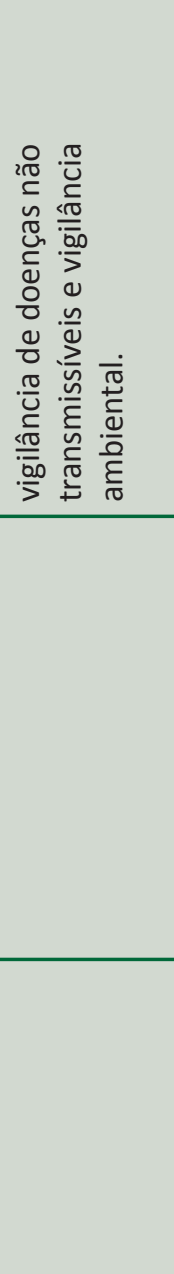 } & 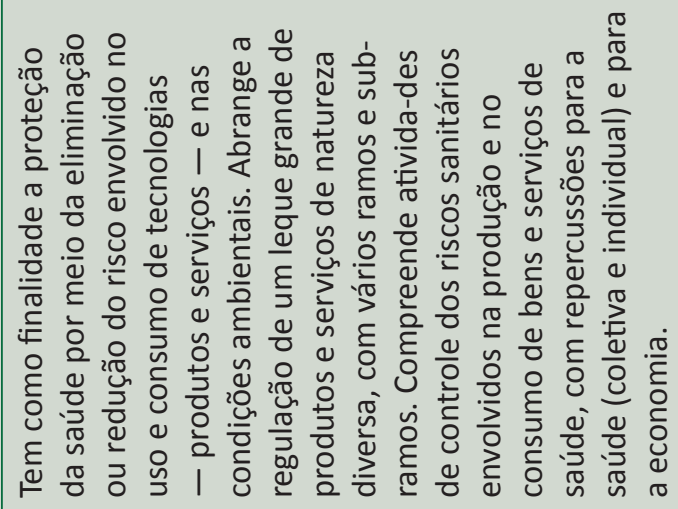 & 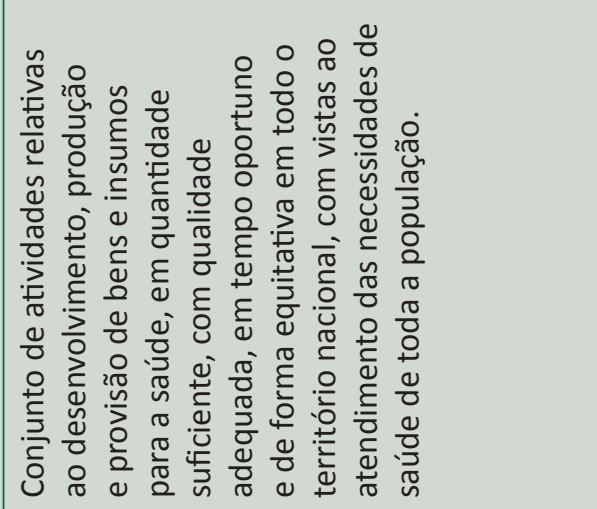 \\
\hline & 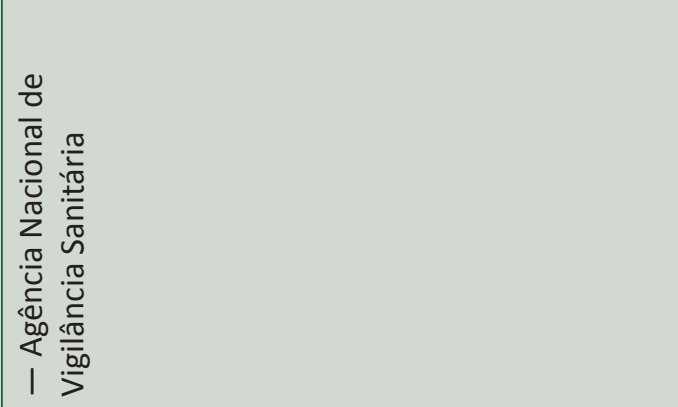 & 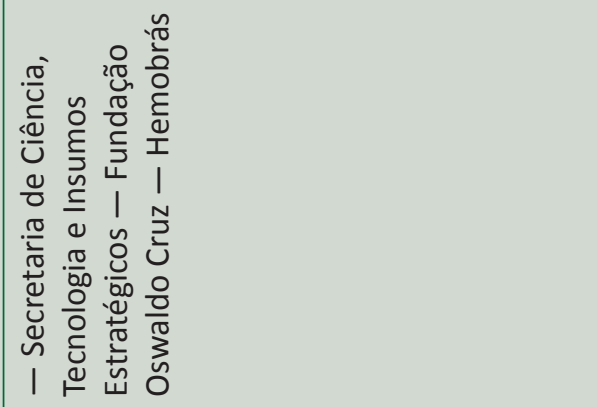 \\
\hline & 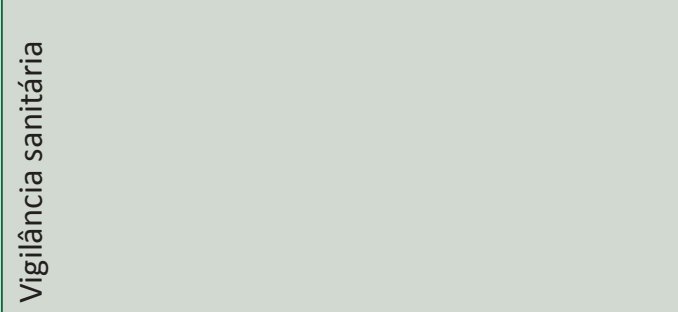 & 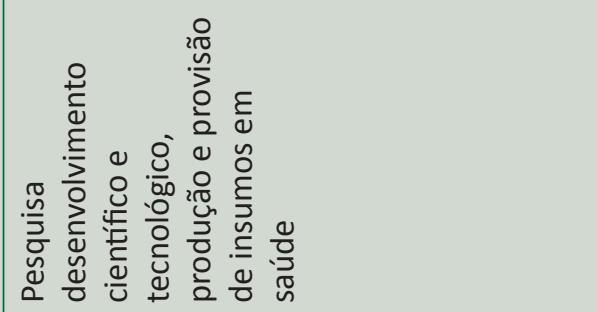 \\
\hline
\end{tabular}




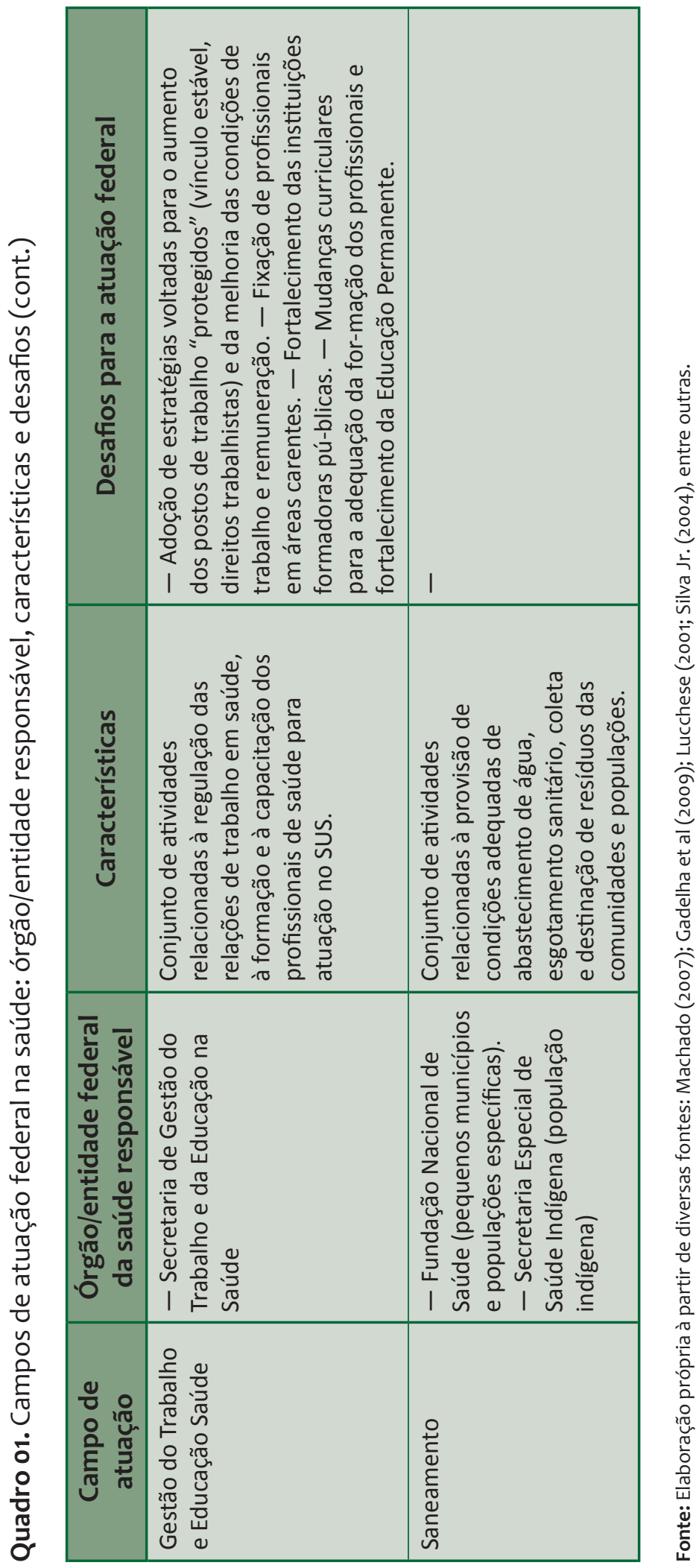




\section{3 | O MODELO DE INTERVENÇÃO FEDERAL NA SAÚDE}

No Brasil, as repercussões dos movimentos de reforma dos Estados Nacionais desencadeados a partir dos anos 1970 em vários países (EVANS, 1993; MAJONE, 1999) foram mais evidentes na década de 1990, sob características específicas. Tal década foi marcada pela liberalização econômica e pelo predomínio de uma agenda de reformas que visou desmontar o modelo de intervenção econômica e social conformado na "era Vargas". Tais reformas se nortearam, no plano econômico, pela abertura de mercados, centralidade das medidas de estabilização fiscal e das privatizações (SALLUM JR, 2004); no plano social, pela expansão de algumas políticas, porém com limites ao crescimento dos gastos públicos e ênfase na descentralização; e no plano administrativo, pela busca de redução do tamanho da administração pública federal e de seu papel de prestação direta de serviços (SANTOS, 2006).

Para Mattos (2006), um novo modelo estatal ${ }^{4}$ - caracterizado pela criação de agências reguladoras, privatizações de empresas estatais, terceirização de funções do Estado, e regulação da economia em uma lógica de defesa da concorrência e correção de "falhas de mercado" - teria se afirmado nos anos 1990, no Governo Fernando Henrique Cardoso. Tal modelo, pautado pela negação do próprio Estado, envolveria um movimento político de "descentralização" do poder do presidente e dos ministros, de mudanças no funcionamento da burocracia e de criação de novos mecanismos jurídico-institucionais de formulação e regulação de políticas, como por meio das agências reguladoras (MATTOS, 2006).

Mais recentemente, no período correspondente ao Governo Lula, houve um movimento de reconfiguração do Estado por meio da retomada de expansão do funcionalismo público (MORAES, SILVA e COSTA, 2009) e da ênfase no fortalecimento da capacidade institucional do Estado (BRASIL, 2003). Ainda que os efeitos desse movimento tenham que ser mais bem estudados, é importante ressaltar que ele não atinge as diversas áreas da administração com a mesma intensidade. Por exemplo, o crescimento do número de servidores federais ativos entre os anos 2000 e 2008 foi bastante expressivo na área da Educação (13,8\%), mas foi pífio na área da Saúde $(3,1 \%)$. Além disso, foi desigual entre órgãos e entidades federais da saúde, privilegiando a realização de concursos para as agências reguladoras e a Fundação Oswaldo Cruz. Houve alguns concursos para contratação de profissionais para os hospitais federais, embora em número insuficiente. Já o nível central do Ministério da Saúde não foi privilegiado com a realização de concursos, sendo que áreas estratégicas permaneceram com alta dependência de consultores, terceirizados e contratados temporariamente (ALBERTO, MACHADO e TEIXEIRA, 2011).

4 Em substituição ao modelo anterior, conformado a partir do governo Vargas e aprofundado no regime militar, que teria se fundado no pensamento autoritário, negando a relevância da democracia para o desenvolvimento. A alternativa formulada por Celso Furtado nos anos 1950, de um modelo democrático de Estado planejador desenvolvimentista, não teria chegado a se constituir plenamente. 
Outro aspecto a ser ressaltado é que, apesar dessa inflexão quanto à visão de Estado, há elementos de continuidade entre os governos FHC e Lula em alguns aspectos, como o arranjo regulatório por meio das agências, que não teria sofrido mudanças substantivas (PACHECO, 2006).

No que concerne à saúde, a análise do modelo de intervenção do Estado no âmbito federal também pode ser feita a partir da consideração de suas quatro macro funções, como planejamento, financiamento, regulação e execução direta de serviços. A análise das mudanças observadas em cada uma delas e na sua articulação é importante para a compreensão das transformações no papel do Estado na política nacional de saúde.

\subsection{Planejamento}

O planejamento em saúde constitui uma macro função fundamental para o direcionamento da política de saúde, ao envolver a tomada de decisões e a proposição de intervenções sobre a realidade sanitária, abrangendo: identificação de necessidades, de prioridades e diretrizes de ação, elaboração de estratégias e planos de intervenção, articulação entre atores e mobilização de recursos necessários para a operacionalização das políticas.

A trajetória histórica da política de saúde das décadas de 1930 a 1980, marcada pela fragmentação institucional, não possibilitava o planejamento nacional integrado. Com a instituição do Sistema Único de Saúde em 1988, previase um fortalecimento do planejamento público que foi, no entanto, prejudicado pelo contexto de reformas do Estado dos anos 1990. Somente ao final daquela década houve certa retomada de estratégias mais consistentes de planejamento estatal nacional, por exemplo, por meio dos Planos de Pronta Ação(PPA), instrumentos previstos na Constituição. As iniciativas de planejamento federal na saúde foram esparsas e mostraram importantes fragilidades, com ausência de planos integrados de médio e longo prazo.

No período correspondente ao Governo Lula (2003 a 2010), houve uma valorização do planejamento estatal, que influenciou positivamente as iniciativas setoriais de planejamento. O movimento de fortalecer o planejamento nacional em um contexto democrático e federativo exigiu do governo federal a ampliação dos debates e busca de formação de consensos com outras esferas de governo e diversos grupos da sociedade (MACHADO, BAPTISTA e LIMA, 2010).

O Ministério da Saúde também procurou fortalecer o seu papel de planejamento por meio de estratégias com propósitos variados, que se expressaram em instrumentos de planejamento específicos. 
Buscou-se a articulação entre planejamento e orçamento, como nos anos 1990, por meio dos PPAs que influenciaram, em cada mandato, as estratégias e instrumentos de planejamento de iniciativa do Ministério da Saúde. O fortalecimento da função planejadora federal foi buscado por meio da construção de um Plano Nacional de Saúde, 2004-2007 (BRASIL, 2004). A valorização da coordenação intergovernamental para o alcance de prioridades da política se traduziu na elaboração do Pacto pela Saúde (2006). Por fim, o esforço de inserção da saúde em um projeto de desenvolvimento em transformação se expressou na construção do Plano Mais Saúde — 2008-2011 (BRASIL, 2009).

Em que pesem as estratégias recentes de fortalecimento do planejamento, persistem lacunas no planejamento federal da política de saúde, entre as quais podem ser citadas: a limitada consideração da dimensão territorial; a fragilidade do planejamento em longo prazo; os baixos investimentos federais; dificuldades de consolidação de uma burocracia federal suficiente e qualificada para o planejamento em saúde nas áreas estratégicas do nível central do Ministério da Saúde; a pouca articulação entre as políticas de saúde e dessas com outras políticas públicas. O equacionamento dessas questões é fundamental para assegurar que o planejamento em saúde possa ter caráter transformador no contexto atual do sistema de saúde brasileiro.

\section{2 | Financiamento}

A função de financiamento se relaciona ao papel do Estado de prover recursos para permitir a oferta de serviços sociais, o que depende da arrecadação de receitas e da execução do orçamento público.

Em que pese a melhoria de alguns indicadores entre 2000 e 2007, o Brasil ainda apresenta baixo gasto público per capita em saúde e baixo comprometimento do gasto público com a saúde, mesmo comparado a outros países da América Latina (WHO, 2010). O grande peso dos gastos privados em saúde no país (estimado em cerca de $58 \%$ do gasto total em 2007) é pouco condizente com o modelo público e universal representado pelo SUS, refletindo problemas estruturais das relações público-privadas e evidenciando o caráter iníquo do financiamento setorial, expresso em distorções como a renúncia fiscal e gastos privados bem superiores aos gastos públicos per capita em saúde (BAHIA, 2009).

Segundo a Constituição de 1988, os três entes federativos têm a responsabilidade de participar do financiamento na saúde. Nos vinte primeiros anos de implantação do SUS, o peso relativo da esfera federal no gasto público em saúde decresceu de mais de 70 \% no início dos anos 1990 para cerca de 45\% em 2008, devido ao aumento da participação das outras esferas de governo, com destaque para os municípios nos anos 1990 e, mais recentemente, para os estados. Esse movimento se 
relacionou ao processo de descentralização e à definição de regras mais rígidas de vinculação das receitas para a saúde para as esferas subnacionais a partir de 2000.

Os gastos executados pelo Ministério da Saúde representam atualmente somente cerca de 20 a $25 \%$ do gasto total em saúde no país. A breve análise do financiamento federal neste capítulo considera os seguintes eixos, sem esgotá-los: (a) a evolução do montante de recursos federais da saúde e sua relação com as fontes de financiamento; (b) a participação dos gastos federais da saúde no PIB; (c) a forma de execução dos recursos do ministério (transferências intergovernamentais ou execução direta); (d) o destino dos recursos por grupos de despesas, campos de atuação e por regiões/unidades da federação.

No que diz respeito ao montante e fontes de recursos do Ministério da Saúde entre 1995 e 2009, observaram-se diferentes momentos. Na segunda metade dos anos 1990 houve oscilações, relacionadas às pressões de políticas econômicas contencionistas e à indefinição de fontes estáveis de financiamento para a saúde (UGÁ e MARQUES, 2005). A aprovação da Contribuição Provisória sobre a Movimentação Financeira (CPMF) em 1997 não foi suficiente para evitar tais oscilações. Já o período de 2000 a 2002 apresentou menor instabilidade, favorecido pelas conquistas anteriores, pela aprovação da Emenda Constitucional n² 29/00 e pelo peso político do Ministro da Saúde no Governo Federal.

No entanto, um incremento significativo no volume de recursos federais, em termos reais, não ocorreu nem após o início da CPMF, devido a um movimento de substituição de fontes, e tampouco após a aprovação da Emenda Constitucional n 29/00, visto que a luta política nos anos subsequentes se deslocou para a regulamentação da sua aplicação e cumprimento. Na realidade, a fórmula da emenda aprovada quanto ao compromisso financeiro da União — vinculando-o à variação do Produto Interno Bruto (PIB) - não pareceu favorável ao aumento do aporte de recursos federais naquele momento (DAIN, 2001; FAVERET, 2003), talvez porque o seu objetivo central tenha sido o aumento dos recursos estaduais.

Entre 2003 e 2005, no início do Governo Lula, em um contexto de restrições impostas pela política econômica, novas oscilações foram observadas na execução orçamentária da saúde. A partir de 2006, no entanto, ocorreu um aumento progressivo dos gastos federais com ações e serviços de saúde. Esse movimento se deve, em grande parte, ao crescimento econômico registrado no país no período 2006-2008, dado o tipo de vinculação estabelecido pela EC 29/00 para os gastos federais.

No que diz respeito à participação da saúde no PIB, nos anos 1990 e 2000 predominou o caráter cíclico do gasto, ou seja, a participação setorial no PIB oscilou de acordo com as variações no crescimento econômico. Apenas em 2009 o gasto em saúde apresentou caráter anticíclico, ou seja, apesar da queda do PIB nacional em decorrência da crise econômica internacional, a execução 
orçamentária com ações e serviços de saúde cresceu em termos absolutos e como proporção do PIB.

Em síntese, as conquistas parciais em termos de fontes de financiamento - como a aprovação da CPMF em 1996 e da EC 29 em 2000 - parecem ter ajudado em médio prazo a proteger o orçamento setorial de oscilações. Porém, a interrupção da CPMF em 2007 e a inadequada regulamentação da EC29/00 no ano de 2011 mantiveram a área da saúde em uma situação de vulnerabilidade em face da conjuntura política e econômica dos governos.

No que concerne à forma de execução de recursos do Ministério da Saúde, nas duas primeiras décadas de implantação do SUS houve progressiva expansão das transferências federais diretas fundo a fundo para estados e municípios (LEVCOVITZ, LIMA e MACHADO, 2001; VIANA, LIMA e OLIVEIRA, 2002; LIMA et al, 2012).

O volume total dos recursos federais diretamente transferidos às esferas nacionais alcançou quase 43 bilhões de reais em $2009^{5}$. Ressalte-se que a proporção de transferências ultrapassou 80\% após a entrada em vigor do Pacto pela Saúde em 2007 e a criação de grandes blocos de financiamento, que radicalizaram as transferências federais para as esferas subnacionais. A modalidade de pagamento federal direto a prestadores de serviços ambulatoriais e hospitalares praticamente deixou de existir. Mesmo os recursos de investimentos federais, antes executados por meio de convênios com estados, municípios ou prestadores, a partir de 2009 passaram a ser em parte repassados por meio de um bloco específico de transferências. A parcela do orçamento federal com ações e serviços de saúde diretamente executada pelo Ministério é atualmente bastante limitada, correspondendo principalmente a gastos com pessoal ativo, gestão de programas nacionais e custeio de órgãos e unidades próprias.

Isso não significa que estados e municípios tenham ampla autonomia para a aplicação dos recursos transferidos, pois persistem condicionalidades e vinculações das transferências a programas nacionais específicos, como formas de indução e de regulação federal sobre as esferas subnacionais.

No que diz respeito ao destino dos recursos por grupos de despesa, vale ressaltar a persistência nos anos 2000 da baixa participação dos investimentos no orçamento do Ministério da Saúde, que no período de 2002 a 2009 oscilou entre 3,4 e 6,3\% em termos dos recursos empenhados com ações e serviços de saúde. Se considerarmos os valores efetivamente pagos, esses percentuais são ainda menores (variam entre apenas 0,5 e 2,1\%), visto que o grupo de investimentos é, em geral, o mais prejudicado nas diferentes etapas da execução orçamentária da saúde, apresentando a menor relação entre valores empenhados e pagos a cada exercício.

5 A discussão do financiamento apresentada neste item baseou-se na análise dos dados do Siga-Brasil (execução orçamentária do Ministério) e da Sala de Situação do Ministério da Saúde (transferências federais), exceto nos casos em que outra fonte for explicitamente citada. 
Os baixos valores dos investimentos federais representam uma limitação importante para a redução das desigualdades em saúde, que seria uma das principais finalidades de atuação federal, dada a heterogeneidade da oferta e do acesso aos serviços no território nacional. Acrescente-se a isso que, conforme apontado em estudo anterior (GADELHA et al, 2009) grande parte dos recursos de investimentos depende de emendas parlamentares, de origem instável e não atrelada a um planejamento nacional de investimentos.

Quanto aos campos de atuação e programas, em termos absolutos a Atenção à Saúde representa o maior volume de recursos, ao compreender os dois principais programas orçamentários do Ministério da Saúde: a assistência de média e alta complexidade (cerca de 50\% do orçamento) e a atenção básica (que variou de 14 a 16,5\% do orçamento, entre 2004 e 2009). Os outros campos de atuação do Estado na saúde - vigilâncias; ciência, tecnologia e insumos estratégicos; gestão do trabalho e da educação em saúde; saneamento - representam parcelas menores do orçamento federal da saúde.

Já em termos relativos, o maior crescimento ocorreu para o campo de ciência, tecnologia e insumos estratégicos, cuja execução orçamentária aumentou mais de $120 \%$ no período, principalmente devido ao aumento de gastos com assistência farmacêutica. Os campos de atenção à saúde e de saneamento também tiveram aumentos acima do crescimento geral da execução orçamentária da saúde. Por outro lado, os gastos com as vigilâncias aumentaram pouco e houve oscilações nos gastos no campo da gestão do trabalho e da educação em saúde entre os anos de 2004 e 2009. No último caso, as dificuldades de execução orçamentária podem se relacionar à criação de uma nova secretaria em 2003 e às inflexões na condução das políticas para essa área.

Uma última perspectiva de análise diz respeito à distribuição dos recursos federais entre as regiões e unidades da federação, considerando a parte do orçamento da saúde passível de apropriação regional ${ }^{6}$. Entre 2002 e 2009, o aumento na execução orçamentária do Ministério da Saúde foi maior para as regiões Norte (59,6\%), CentroOeste $(55,4 \%)$ e Nordeste $(49,2 \%)$, enquanto as regiões Sudeste e Sul tiveram menores aumentos.

Essa informação pode sugerir, a princípio, um movimento no período de maior destinação de recursos federais para regiões historicamente menos favorecidas, o que pode ter relação, entre outros fatores, com aumento na oferta de ações e serviços de saúde.

6 A parcela "regionalizável" correspondeu no período de 2002 a 2009 a cerca de 63 a $70 \%$ do orçamento do Ministério da Saúde, incluindo as despesas de custeio ou investimento cujo destino para as regiões e/ou UFs é conhecido, sejam transferências a outras esferas de governo, pagamentos diretos a prestadores, convênios ou emendas parlamentares. Em geral, não incluem os gastos com gestão centralizada de órgãos ou programas federais, pagamento de pessoal ativo, despesas com inativos/pensionistas, pagamentos de dívidas e outras operações especiais. 
No entanto, a análise em termos de recursos federais per capita sugere que, em 2009, ainda persistiam desigualdades importantes entre as regiões e as unidades da federação. Tais informações devem ser analisadas com cautela, pois a discussão do papel redistributivo do governo federal e da equidade no financiamento da saúde exigiria a consideração de outros aspectos: a distribuição da totalidade dos recursos federais e as variações nas necessidades de saúde (UGÁ e MARQUES, 2005); aspectos referentes ao federalismo fiscal (LIMA, 2007); a diversidade interna às macrorregiões, estados, regiões metropolitanas e municípios; as relações público-privadas no financiamento da saúde (BAHIA, 2009); a distribuição dos recursos entre grupos sociais.

\section{3 | Regulação}

Neste texto, o termo regulação é usado para designar a função federal de modulação do sistema nacional de saúde, no sentido de controlar procedimentos e processos ou buscar uma maior homogeneidade de características ou de resultados no território, por ação federal direta ou por meio da indução de práticas de gestores de outras esferas, prestadores de serviços e agentes privados (MACHADO, 2007a).

A regulação estatal em saúde pode ser analisada sob diferentes perspectivas, por exemplo, em relação ao tipo de organização ou esfera alvo da regulação (ex: secretarias de saúde, prestadores de serviços, operadoras de planos privados) ou em relação ao objeto de intervenção (ex: regulação assistencial, regulação sanitária, regulação de preços de insumos, regulação do trabalho em saúde).

Para fins deste texto, serão discutidas principalmente as estratégias de regulação federal voltadas para: sistemas estaduais e municipais de saúde; prestadores de serviços ao SUS e mercados de planos e seguros de saúde. De forma mais breve, serão abordadas mudanças relativas à regulação nos campos da vigilância sanitária, recursos humanos e insumos em saúde.

Nos vinte primeiros anos de implantação do SUS, observa-se a sobreposição de antigas e novas estratégias de regulação, assim como mudanças na natureza e escopo da regulação federal sobre a política de saúde. Com o avanço da descentralização, a regulação federal direta sobre os prestadores de serviços se reduziu e o Ministério da Saúde se voltou principalmente para a modulação dos sistemas estaduais e municipais de saúde. Também foram adotadas novas estratégias de regulação de mercados, porém sob características específicas e com muitas fragilidades.

Durante os anos 1990, em face do peso da União no financiamento da saúde e do protagonismo federal na condução da descentralização setorial, o Ministério da Saúde manteve expressivo poder de regulação sobre as secretarias estaduais e municipais de saúde. As principais estratégias de regulação federal nesse sentido, em geral associadas, foram a emissão de normas e portarias e os mecanismos financeiros 
de indução de políticas, com repercussões para a configuração de sistemas estaduais e municipais de saúde (LEVCOVITZ et al, 2001; MACHADO, 2007; BAPTISTA, 2007). Outras estratégias de regulação dos sistemas relevantes no período foram: definição de prioridades e metas no âmbito nacional, cooperação e apoio técnico a estados e municípios, fomento federal a práticas inovadoras, ações de auditoria, controle e avaliação.

Nos anos 2000, houve continuidades no que se refere à regulação federal sobre os sistemas estaduais e municipais de saúde, persistindo o esforço federal de indução de políticas no âmbito subnacional. O crescimento acentuado da quantidade de portarias emitidas pelo Ministério da Saúde, observado nos anos 1990, prosseguiu nos anos 2000, com pequenas oscilações anuais. O dado sugere a persistência de uma importante atuação normativa federal, visto que muitas portarias se voltam para a indução de políticas e regulação de práticas dos gestores estaduais, municipais e prestadores de serviços.

Isso ocorreu porque, concomitantemente ao aumento das transferências intergovernamentais de recursos, o Ministério da Saúde procurou usar normas e incentivos financeiros para manter seu poder de decisão sobre a utilização de recursos federais transferidos, de forma que as prioridades nacionais se expressassem nos estados e municípios. Tal modelo levou a uma fragmentação das transferências federais em um número cada vez maior de parcelas até a emissão do Pacto pela Saúde em 2006 (BRASIL, 2006). A criação de grandes blocos de financiamento em 2007, no entanto, não rompeu totalmente com a lógica anterior de regulação federal, pois a adesão às normas e programas federais continuou a ser utilizada para fins de cálculo dos recursos a transferidos para as esferas subnacionais (LIMA et al, 2012).

No que diz respeito aos prestadores de serviços ao SUS, a partir de 2004 deixou de existir a modalidade de remuneração direta do Ministério da Saúde a serviços ambulatoriais e hospitalares privados. Assim como os recursos, as responsabilidades de regulação sobre prestadores de serviços foram em sua maioria transferidas para estados e municípios.

Ainda assim, a atuação federal continuou a repercutir sobre os prestadores por meio de quatro estratégias principais: (a) a emissão de portarias que regulamentam o funcionamento e os critérios técnicos de credenciamento de serviços ao SUS (ex: serviços de alta complexidade); (b) a administração das tabelas de remuneração de serviços ambulatoriais e hospitalares, que influenciam os preços praticados por estados e municípios e o interesse dos prestadores em oferecer serviços ao SUS; (c) a manutenção dos sistemas nacionais de informações sobre oferta e produção de serviços, que subsidiam o monitoramento dos prestadores pelos gestores das três esferas; (d) o desenvolvimento de ações diretas de auditoria federal. 
Ademais, a complexidade dos processos de estabelecimento de convênios com prestadores privados "não-lucrativos", dadas as implicações tributárias da concessão de certificados de filantropia, fez com que o Ministério da Saúde criasse ao final dos anos 2000 um departamento específico com a finalidade de interlocução e análise da situação desse grupo de prestadores ${ }^{7}$

Assinale-se ainda que a implantação do Programa Farmácia Popular — particularmente da vertente das farmácias privadas conveniadas, que se expandiu a partir de 2006 — impõe novas exigências de regulação federal, dado o deslocamento da dispensação de medicamentos para fora do espaço das unidades de saúde e o expressivo volume de recursos federais repassados para o comércio varejista de medicamentos.

A regulação do mercado de planos e seguros de saúde vem sendo operada por meio da Agência Nacional de Saúde Suplementar (ANS) desde o início dos anos 2000, cuja atuação não apresentou inflexões marcantes desde então, embora possam ter ocorrido mudanças incrementais que exigem análises mais específicas ${ }^{8}$. A atuação da ANS tem sido marcada por: sistematização de informações sobre o segmento de planos e seguros de saúde; regras financeiras para o funcionamento das operadoras e seguradoras no mercado; regulamentação do conteúdo dos contratos e do seu cumprimento; regulação dos preços dos planos contratados individualmente.

Dados oficiais mostram que houve nos anos 2000 crescimento do número de beneficiários de planos de assistência médica e de planos exclusivamente odontológicos. Evidencia-se que, de forma concomitante à expansão das políticas e serviços públicos no âmbito do SUS, também tem ocorrido uma expansão de serviços e planos privados de saúde. Tal constatação implica a reflexão sobre a direcionalidade e os propósitos da regulação desse mercado pelo Estado, ou seja, sobre o sentido da própria existência e da atuação da ANS.

A regulação sanitária é outra área tradicional de atuação do Estado, no Brasil designada sob o termo vigilância sanitária, que engloba ações direcionadas a ramos produtivos de caráter muito distinto: medicamentos, alimentos, cosméticos, materiais de limpeza, entre outros. As políticas nessa área no âmbito federal estão sob responsabilidade direta da Agência Nacional de Vigilância Sanitária, cujo modelo regulatório não sofreu inflexões expressivas desde a sua criação. A complexidade da regulação sanitária se relaciona não apenas à diversidade de mercados a serem regulados, mas a fatores como: os fortes interesses econômicos na saúde, as implicações das decisões para o comércio internacional e a dependência de intensa articulação

7 Departamento de Certificação de Entidades Beneficientes de Assistência Social em Saúde, no âmbito da Secretaria de Atenção à Saúde. Ver estrutura do Ministério da Saúde constante no Decreto 7336 de 19/10/2010.

8 Para alguns autores, a atuação das agências reguladoras federais na área de infraestrutura e social nos anos 2000 foi marcada pelo predomínio de continuidades e não conformação de um modelo regulatório alternativo, mesmo após a mudança de governo em 2003. A propósito, ver os trabalhos de Mattos (2006) e Pacheco (2006). 
com os segmentos produtivos nacionais e com outros órgãos de governo (incluindo as próprias secretarias do Ministério da Saúde). Por vezes ocorrem impasses entre decisões técnicas da ANVISA relativas a riscos sanitários, empresários e representantes do governo em questões de grande importância. Um exemplo recente foi a questão da produção de alimentos transgênicos. Outro exemplo concerne aos fluxos de autorização para produção e comercialização de medicamentos. Nesse âmbito, são comuns, de um lado, as queixas por parte da indústria ou outros órgãos de governo sobre as exigências e os longos prazos da ANVISA; de outro, a argumentação da Agência de que tais controles são fundamentais para a redução dos riscos de danos à saúde.

A esse propósito, vale mencionar a adoção nos anos 2000 de novas estratégias de regulação federal coordenadas pela Secretaria de Ciência, Tecnologia e Insumos Estratégicos (SCTIE) criada em 2003 na estrutura do Ministério da Saúde. A partir de 2007, aumenta a ênfase no fortalecimento do complexo industrial da saúde no país, com desdobramentos em termos da criação de novas estruturas — incluindo a criação do Grupo Executivo do Complexo Industrial da Saúde (GECIS) - e regras de incentivo à produção nacional de insumos relevantes para a saúde. Nesse contexto de estímulo ao aumento da produção nacional de medicamentos e outros insumos para a saúde, é fundamental a maior articulação entre as secretarias do Ministério (particularmente a SCTIE e a SAS), a ANVISA e outros ministérios federais ligados à área industrial, visto que tal expansão deve se dar de acordo com as necessidades de saúde e sob mecanismos regulatórios que garantam a qualidade dos produtos e a minimização de riscos sanitários.

Outro campo em que houve expansão da regulação federal associada à criação de uma nova secretaria do Ministério da Saúde foi o de gestão do trabalho e da educação na saúde. No âmbito da gestão do trabalho, cabe mencionar de um lado as iniciativas de apoio à desprecarização das relações de trabalho em saúde e os debates sobre negociações salariais e perspectiva de carreiras públicas (com alcance limitado); e, de outro, o polêmico apoio do Ministério, particularmente a partir de 2007, à adoção da Fundação Estatal de direito privado como modelo de gestão de serviços públicos se saúde.

No que concerne à formação de profissionais, intensificam-se as propostas e os programas voltados para a reestruturação curricular e educação permanente de profissionais de saúde, muitas vezes envolvendo parcerias entre o ministério da Saúde e da Educação.

A expansão da atuação federal nessas últimas duas áreas — de insumos e recursos humanos - se deu sob um modelo de regulação por dentro da estrutura ministerial, visto que envolveu a criação de novas secretarias, regulamentações por meio de portarias e parcerias do Ministério da Saúde com outros órgãos federais. Configura-se nessas áreas, portanto, uma regulação por dentro da Administração Direta, já que não foram criadas outras agências de saúde além das existentes. 
As fundações públicas vinculadas ao Ministério da Saúde não se destacaram nessa reconfiguração da função regulatória federal, porque não foram originalmente concebidas com tal tipo de função. A Fundação Oswaldo Cruz, com atuação na área de ciência e tecnologia em saúde, continuou a exercer suas atribuições no ensino, pesquisa, cooperação técnica, inovação e produção de insumos estratégicos. Já a Fundação Nacional de Saúde passou por um progressivo esvaziamento de suas funções, primeiro em relação à vigilância epidemiológica (em 2003), e depois na área de saúde indígena (em 2010), por meio da criação de secretarias específicas na estrutura de administração direta do Ministério da Saúde.

\subsection{Prestação Direta de Ações e Serviços de Saúde}

Nos anos 1990, houve uma redução do papel federal na prestação direta de serviços e ações de saúde, coerente com a diretriz do SUS de descentralização políticoadministrativa e com as diretrizes da reforma da Administração Pública federal década (MACHADO, 2007a). Portanto, no início dos anos 2000 a quantidade de serviços de saúde sob administração federal já era reduzida, mantendo-se relativamente estável nos anos seguintes.

Em agosto de 2010, segundo dados do Cadastro Nacional dos Estabelecimentos deSaúde (CNES) os estabelecimentos de saúde federais representavam menos de $0,2 \%$ do total do país. Tais estabelecimentos se distribuíam desigualmente no território nacional, com um maior número absoluto nos estados do Rio de Janeiro, Rio Grande do Sul e Minas Gerais. Em termos relativos, o estado de Roraima apresentava um maior peso dos serviços federais, que representavam 4,6\% dos estabelecimentos de saúde no estado. Entre as unidades federais, predominam os hospitais, embora ainda existam na administração federal unidades ambulatoriais especializadas, unidades básicas, serviços de apoio diagnóstico e terapêutico, entre outros.

Apesar do reduzido número de unidades, os hospitais federais compreendem cerca de $4 \%$ dos leitos disponíveis ao SUS no país, envolvendo serviços de referência regional ou nacional. Cabe destacar a situação dos hospitais federais localizados no município do Rio de Janeiro que, por sua condição histórica de excapital do país, apresenta um maior número de serviços federais. Nos anos 1990 e início dos anos 2000, houve tensões e instabilidade relacionadas à descentralização de tais hospitais.

Em 2003, permaneciam sob gestão federal três institutos especializados de referência nacional - o do Câncer (INCA), o de Traumato-Ortopedia (INTO) e o de Cardiologia de Laranjeiras (INCL) - , os hospitais de Bonsucesso e dos Servidores do Estado. Tais unidades têm diferentes perfis de atendimento, estatuto político e possibilidades de captação de recursos. O INCA é o que apresenta maior projeção 
nacional como referência assistencial, além de sua importância no apoio à formulação de políticas e no desenvolvimento de pesquisas. Já o INTO aumentou sua projeção política e recebeu investimentos expressivos no segundo governo Lula, voltados para a construção de uma nova sede.

Ressalte-se como um acontecimento político relevante no período recente a "refederalização" de quatro hospitais gerais situados no município do Rio de Janeiro: Andaraí, Cardoso Fontes, Ipanema e Lagoa. Tais hospitais haviam sido transferidos para a gestão municipal no início dos anos 2000, porém enfrentaram problemas nos anos subsequentes. Em 2005, após um período de crise que culminou com a intervenção federal no município, os hospitais voltaram para a gestão federal ${ }^{9}$. Entre 2006 e 2010, houve iniciativas de fortalecimento da gestão desses hospitais, incluindo parcerias com hospitais privados e debates sobre a possibilidade de adoção de um novo modelo jurídico-institucional de fundações estatais de direito privado.

Cabe ainda destacar a existência de dois hospitais federais de referência ligados a Fundação Oswaldo Cruz, também localizados no Rio de Janeiro: o Instituto de Pesquisa Clínica Evandro Chagas (IPEC), especializado em doenças infecciosas; e o Instituto Fernandes Figueira (IFF), especializado em atenção materno-infantil.

Ressalte-se que os três institutos nacionais, além das atividades assistenciais, desempenham atividades de ensino e pesquisa e têm atribuições de apoio à formulação de políticas nas suas referidas áreas. Os institutos ligados à Fundação Oswaldo Cruz tiveram uma trajetória histórica de desenvolvimento de atividades assistenciais acopladas à pesquisa e ao ensino nas suas áreas de especialidade.

Além da prestação direta de serviços assistenciais, a esfera federal mantém atividades de produção direta de insumos estratégicos em unidades de referência ligadas à Fundação Oswaldo Cruz, como os institutos de tecnologia em Fármacos (Farmanguinhos) e em imunobiológicos (Biomanguinhos). Ressalte-se ainda o início da operação da Empresa Brasileira de Hemoderivados e Biotecnologia (Hemobrás), cuja fábrica está em construção e tem inauguração prevista para o ano de 2014.

9 A crise, de caráter assistencial, administrativo e político, teve relação com a baixa prioridade conferida à saúde pela gestão municipal e com a exacerbação de conflitos intergovernamentais e interpartidários. A intervenção federal no município do Rio de Janeiro foi autorizada por decreto presidencial e capitaneada pela equipe do Ministério da Saúde na gestão Humberto Costa, após um período de impasses relativos à situação da atenção hospitalar no município. Além dos quatro ex-hospitais federais, a intervenção abrangeu os hospitais municipais de emergência Miguel Couto e Souza Aguiar. Um mês após o decreto presidencial, o Supremo Tribunal Federal declarou a inconstitucionalidade da requisição dos hospitais municipais e o Ministério da Saúde passou a se concentrar nas medidas para a refederalização das quatro ex-unidades federais (ALVES e MACHADO, 2007). 


\section{4 | ARTICULAÇÃO DA POLÍTICA DE SAÚDE COM OUTRAS POLÍTICAS PÚBLICAS}

A Constituição do Brasil afirma que a saúde deve ser garantida mediante políticas econômicas e sociais amplas. Existe uma ampla discussão sobre os determinantes sociais da saúde ${ }^{10}$ e suas implicações, visto que a melhoria das condições de saúde de uma população depende de políticas públicas integradas que muitas vezes extrapolam o setor saúde e, portanto, a governabilidade direta das autoridades sanitárias.

Em termos gerais, quase todas as políticas públicas podem repercutir direta ou indiretamente sobre a saúde das pessoas. Isso evidencia que assumir seriamente o propósito de melhoria da situação de saúde do conjunto da população implica uma profunda reorientação da atuação do Estado, o que requer decisões políticas dos governos, respaldadas pela sociedade.

De forma sucinta, identificam-se quatro grupos de políticas com repercussões relevantes sobre a saúde, que requerem intensa articulação intersetorial:

1. Políticas econômicas, industriais e de trabalho — as políticas econômicas obviamente repercutem sobre condições sociais da população, incluindo as condições de saúde, de várias formas, além de delimitarem as possibilidades e limites (institucionais e financeiros) das políticas sociais. Cabe assinalar a importância das políticas industriais para a garantia da provisão de insumos adequados e suficientes para o sistema de saúde e os efeitos das políticas na área do trabalho e renda, tanto para a saúde da população quanto para o funcionamento dos mercados de trabalho no setor saúde. Ressalte-se ainda que o setor saúde, por outro lado, oferece oportunidades relevantes em termos do desenvolvimento industrial do país e da geração de empregos qualificados, o que traz a possibilidade de uma combinação virtuosa entre as dimensões econômica e social da saúde.

2. Políticas de habitação, saneamento e outras de infraestrutura urbana ou rural - tais políticas têm uma importância enorme para a situação de saúde da população. Por exemplo, são amplamente reconhecidos os efeitos do abastecimento de água e do saneamento adequado para a morbidade de crianças (BARRETO et al, 2007). O Brasil ainda apresenta um déficit habitacional e

10 Ver por exemplo o site e as publicações da Comissão Nacional sobre Determinantes Sociais da Saúde (http:// www.determinantes.fiocruz.br/). 
de saneamento muito importante, o que torna fundamental o investimento nessas áreas, cuja responsabilidade historicamente tem sido fragmentada entre vários ministérios federais. O Plano de Aceleração do Crescimento - PAC — lançado em 2007 e atualmente sob coordenação do Ministério do Planejamento, Orçamento e Gestão, previu uma série de projetos nesse sentido. No que concerne ao Ministério da Saúde, cabe assinalar que existem projetos de investimentos em saneamento sob responsabilidade da FUNASA (pequenos municípios, comunidades quilombolas, ribeirinhos, áreas de risco para determinadas doenças) e da Secretaria Especial de Saúde Indígena (saneamento em áreas indígenas). Parte desses projetos foi apresentada no âmbito do PAC-FUNASA, lançado em 2007 e incorporado em 2008 como um dos eixos do Plano Mais-Saúde (2008-2011).

3. Políticas de Educação — é amplamente reconhecida a relação entre níveis de escolaridade e a situação de alguns indicadores de saúde. Em um país com indicadores educacionais ainda precários (em termos de acesso e qualidade), os investimentos em educação e a articulação intersetorial podem ter efeitos bastante positivos para a saúde. Por outro lado, crianças e jovens que recebam cuidados de saúde adequados às suas necessidades podem apresentar condições mais favoráveis à aprendizagem. Por fim, outra dimensão relevante da articulação Saúde-Educação diz respeito à formação dos profissionais de saúde, que se configura atualmente como uma questão crítica para o Sistema Único de Saúde.

4. Políticas de combate à pobreza e de expansão de direitos de grupos em situação de vulnerabilidade social - considerando a existência no Brasil de um número expressivo de pessoas pobres, as políticas de combate à pobreza podem ter efeitos bastante importantes sobre a saúde. As políticas de saúde, por sua vez, podem contribuir para a redução da pobreza, compreendida em suas múltiplas facetas. Na última década, houve várias tentativas de articulação entre iniciativas de combate à pobreza e expansão de ações de saúde. Ressaltem-se ainda as estratégias voltadas para grupos específicos em situação de vulnerabilidade - população prisional, jovens em situação de risco de violência, população negra, grupos de gays, lésbicas, bissexuais, travestis e transexuais (GLBT) - que têm exigido políticas de saúde específicas, em articulação com outras políticas públicas. 
Enfim, ter um povo com saúde implica um projeto de desenvolvimento nacional e de atuação do Estado que compreenda e articule: políticas econômicas sólidas, voltadas para o Bem-Estar Social; políticas universais consistentes em várias áreas (Previdência, Saúde, Educação); políticas focalizadas voltadas para grupos em condições de vulnerabilidade (combate à pobreza, expansão de direitos e atenção diferenciada a grupos específicos).

\section{5 | DESAFIOS ESTRATÉGICOS PARA A RECONFIGURAÇÃO DO PAPEL FEDERAL NA SAÚDE}

A identificação de desafios estratégicos para reconfiguração da atuação federal na saúde parte dos pressupostos inicialmente anunciados e das discussões apresentadas ao longo do capítulo. Assume-se como ponto de partida o marco constitucional-legal e a afirmação da saúde como direito de cidadania, a ser assegurada mediante políticas econômicas e sociais integradas e por uma política nacional de saúde norteada pelos princípios de universalidade e integralidade da atenção.

Reconhecer que as diretrizes constitucionais relativas à proteção social e à saúde não estão plenamente concretizadas implica explicitar fragilidades e admitir a necessidade de reorientação de rumos na atuação do Estado e nas suas relações com a sociedade. A configuração do sistema de saúde depende, em última análise, do modelo de país, de sociedade e de cidadania que se pretende alcançar. Ou seja, implica um projeto coletivo de transformação social, cujo sentido foi apontado pela Reforma Sanitária e pela Constituição de 1988, mas que tem sido sufocado por características histórico-estruturais da sociedade brasileira, como as marcantes desigualdades socioeconômicas, sob antigas e novas roupagens.

O Brasil apresenta um sistema universal de saúde, porém mais de 50\% dos gastos em saúde são privados. As elites políticas e burocráticas, os trabalhadores organizados, os profissionais da saúde e as classes médias podem defender o Sistema Único de Saúde em tese, mas contam com planos ou seguros de saúde fortemente subsidiados pelo Estado. Parte dos trabalhadores que tem experimentado certa ascensão social nos últimos anos - em função do contexto de crescimento econômico associado à redução da pobreza - aspira o acesso a serviços privados de saúde. Embora várias pesquisas com usuários do SUS apontem bons níveis de satisfação com os serviços obtidos, outras pesquisas por amostragem da população sugerem uma imagem negativa do sistema público de saúde, não sendo possível afirmar que existe amplo reconhecimento, legitimidade, identidade e defesa do SUS pelo conjunto da sociedade. Ainda que os fatores explicativos para essa situação sejam de várias ordens, o nível de confiança no Estado para a garantia de serviços públicos de qualidade em geral não é alto. Tal fato, associado a fortes interesses econômicos, restringe as possibilidades 
de aumento da carga de impostos, de realização de uma reforma tributária em um sentido mais redistributivo e de retirada de determinados subsídios diretos e indiretos ao setor privado em áreas críticas, como a da saúde.

Nesse contexto, cabe indagar se é possível concretizar as diretrizes constitucionais relativas à Seguridade e ao SUS por meio de mudanças incrementais - busca de maior efetividade das políticas, melhoria do acesso e da qualidade dos serviços públicos - ou se alcançá-las implicaria em um novo momento de inflexão no pacto social, com adoção de estratégias políticas mais radicais.

Sem pretender responder tal questão, é possível imaginar dois cenários para o sistema de saúde brasileiro em 2030. Em um primeiro cenário, considerado desejável e otimista (porém mais difícil de ser alcançado) assume-se a radicalização das diretrizes constitucionais relativas à proteção social, à Seguridade e ao Sistema Único de Saúde. Em um segundo cenário, mais conservador, prevê-se a realização de mudanças incrementais nas políticas sociais e de saúde, de forma a melhorar as condições de vida da população, porém sem romper com algumas distorções históricoestruturais do sistema de proteção social brasileiro.

A seguir discutem-se os principais desafios estratégicos para a reconfiguração da atuação federal na saúde, considerando o cenário desejável (otimista). O enfrentamento limitado ou parcial desses desafios torna mais provável o segundo cenário (conservador).

No cenário otimista, o Brasil seria em 2030 um país bem situado no contexto mundial, com um modelo de desenvolvimento que articule as dimensões: econômica (crescimento sustentado, mesmo que gradual); social (orientado para o bem-estar social, com consolidação dos direitos universais, redução da pobreza e das desigualdades sociais) e política (consolidação da democracia, aumento da participação da população por via representativa e direta). Haveria de fato um Estado de Bem-Estar Social brasileiro, orientado para o pleno emprego (com condições dignas), alicerçado em políticas universais abrangentes e inclusivas (Previdência, Saúde, Educação) e em políticas de infraestrutura social (Saneamento, Habitação), articuladas a políticas de combate à pobreza, direcionadas para grupos específicos. Ademais, a dimensão territorial teria que ser fortalecida nas políticas públicas, dada a imensa heterogeneidade e as desigualdades observadas no país.

Nesse cenário, o Sistema Único de Saúde teria ampla legitimidade social e a imensa maioria dos brasileiros — incluindo camadas médias urbanas — teria confiança nos serviços públicos de saúde ou mesmo a preferência em utilizá-los. Ainda que as condições para o alcance de tal cenário extrapolem muito a governabilidade dos atores setoriais, alguns desafios estratégicos relativos à reconfiguração da atuação federal na saúde podem ser identificados no que concerne à capacidade institucional e ao modelo de intervenção federal e aos campos de atuação do Estado. 
Realiza-se neste texto uma primeira aproximação a esses dois grandes grupos de desafios, sendo necessário o desenvolvimento de estudos específicos que apoiem as mudanças na ação federal no que concerne aos aspectos aqui abordados.

Os principais desafios relacionados à capacidade institucional e ao modelo de intervenção federal seriam:

1. Planejamento - necessidade de fortalecimento da capacidade de planejamento em saúde no âmbito nacional, em uma perspectiva mais estratégica, integrada e de longo prazo. Isso exige a conformação de uma burocracia sólida, qualificada e estável no âmbito federal, com formação técnico-política na área de planejamento e gestão pública da saúde e com capacidade de diálogo e articulação com outros atores setoriais e extrassetoriais (outras áreas do governo federal, esferas de governo, academia, movimentos sociais, entidades profissionais, indústrias da saúde, prestadores de serviços, entre outros). Requer a elaboração de planos voltados para a reconfiguração do sistema de saúde no território nacional (expansão da oferta de serviços com mudanças no modelo de atenção e nas relações público-privadas), que considerem as mudanças demográficas e epidemiológicas, a dimensão territorial e que se associem à realização de investimentos federais expressivos.

2. Financiamento - garantia de estabilidade das fontes de financiamento da saúde e de ampliação dos recursos federais em termos de montante, participação no gasto público e no PIB; expansão da participação pública no gasto total. Para radicalizar o caráter universal do sistema, seria importante perseguir uma meta de financiamento majoritariamente público da saúde (ao menos 70\%, com proporção de gastos privados de no máximo 30\%), com participação mais expressiva dos gastos em saúde no PIB (cerca de 10\%). Além disso, considerando a heterogeneidade e as desigualdades do setor, seria desejável uma nova expansão da participação federal nos gastos em saúde para ao menos 50\% do gasto público total, assegurando-se a manutenção da participação dos municípios e o aumento da participação dos estados ${ }^{11}$. Ademais, seria importante: a progressiva retirada dos subsídios ao segmento de assistência médica suplementar

11 Principalmente dos estados que ainda não cumprem a determinação constitucional estabelecida pela emenda n. 29 / 2000, de aplicação de 12\% de suas receitas correntes líquidas na saúde. Assinale-se que nos anos 2000, vários estados aumentaram a sua participação no financiamento da saúde, porém isso ainda tem sido bastante heterogêneo em termos de montante e tipos de despesas priorizadas. 
(isenção tributária e outras formas); a adoção de critérios mais firmes que condicionem o repasse de recursos a entidades ou prestadores privados (exigência de atendimento exclusivo ou efetivamente majoritário ao SUS, eliminação de duplas portas de entrada); o aumento dos investimentos federais em áreas estratégicas e segundo critérios de equidade (e não somente segundo a lógica da indução da adesão a programas federais isolados, que podem acirrar desigualdades); entre outras mudanças.

3. Regulação - necessidade de fortalecimento da capacidade regulatória do Estado nos diversos âmbitos, o que inclui, sobretudo, rever os propósitos e a direcionalidade da regulação sobre os mercados em saúde e destrinchar as diversas formas de imbricamento entre o público e o privado, às vezes camufladas sob a generalidade da expressão "parcerias público-privadas".

- No que se refere aos planos e seguros privados, além da eliminação dos subsídios financeiros, seria fundamental rever as finalidades de atuação da ANS e subordiná-la a um projeto mais geral de transformação do sistema de saúde no sentido do fortalecimento do caráter público e universal do sistema e de contenção do crescimento dos mercados privados, sob intensa regulação estatal.

- Quanto aos prestadores privados de serviços ao SUS, é importante assegurar efetivamente a finalidade pública da prestação, o que implica critérios mais rigorosos de seleção, contratualização e regulação desses prestadores, visando evitar subsídios cruzados e a apropriação privada de recursos públicos.

- No que diz respeito às atividades econômicas que têm repercussões sobre a saúde (atividade agrícola, indústria de alimentos, indústria automobilística), a partir de uma visão de promoção da saúde é fundamental fortalecer as pesquisas sobre riscos sanitários e a regulação sanitária, de modo que os interesses da saúde coletiva não sejam subordinados aos interesses comerciais.

- Já no que concerne às indústrias de insumos para a saúde (medicamentos, reagentes, equipamentos), é possível apostar em uma combinação virtuosa entre as políticas de fomento à indústria nacional e as necessidades de atenção 
à saúde da população, desde que as prioridades sanitárias sejam efetivamente consideradas nas decisões relativas ao desenvolvimento industrial nos diferentes segmentos relevantes para a saúde.

- Outra dimensão da regulação federal — relativa à configuração dos sistemas estaduais e municipais e saúde - está intimamente imbricada à questão da coordenação federativa da política de saúde, que em um contexto democrático requer o fortalecimento de relações intergovernamentais mais equilibradas e cooperativas.

4. Produção direta de serviços e de insumos - ainda que o papel federal de prestador direto de serviços de saúde tenha apresentado expressiva retração nos vinte primeiros anos de implantação do SUS, em face do processo de descentralização, ainda existem unidades federais em algumas unidades da federação, destacando-se os hospitais federais situados no Rio de Janeiro (caracterizados no Quadro 3). Alguns desses hospitais já passaram por processos de transferência para instâncias subnacionais que não foram bem sucedidos - dado o seu importante porte, complexidade e volume de recursos que mobilizam- retornando à esfera federal. No horizonte temporal previsto - 2022 e 2030- é importante investir no fortalecimento dos elementos diferenciais desses hospitais.

- Alguns deles devem ser reafirmados como institutos nacionais de excelência, que articulam atividades assistenciais especializadas com pesquisa clínica, ensino/ formação e desenvolvimento de projetos assistenciais pioneiros, além de apoiarem o Ministério da Saúde na formulação de políticas e definição de normas técnicas para suas respectivas áreas. Esse é o caso dos institutos nacionais do Câncer (INCA), de Cardiologia (INCL), de Traumato-Ortopedia e dos dois hospitais especializados ligados à Fundação Oswaldo Cruz (o Instituto Fernandes Figueira, na área materno-infantil; e o Instituto de Pesquisa Clínica Evandro Chagas, em doenças infecciosas). No caso dos outros seis hospitais federais é importante investir em torná-los centros de referência assistencial e fortalecer atividades correlatas de pesquisa clínica e formação em serviço.

- Já no que concerne à atividade federal na produção direta de insumos para saúde- com destaque para Biomanguinhos e 
Farmanguinhos, da Fiocruz, e para a Hemobrás -,é fundamental a realização de investimentos para que se afirmem como unidades vinculadas à pesquisa e inovação, que produzam insumos estratégicos de qualidade para o atendimento das necessidades do sistema público de saúde.

O segundo grupo de desafios estratégicos se relaciona aos campos de atuação do Estado na saúde, que são interdependentes. Sem pretender esgotar esse tema, apontam-se sumariamente alguns desafios relativos aos campos da atenção à saúde, gestão do trabalho e da educação e à vigilância epidemiológica.

No que diz respeito à atenção à saúde, destaque-se a importância de consolidação de um novo modelo de atenção, que articule promoção da saúde, prevenção, tratamento e reabilitação, considerando as características e as mudanças demográficas e epidemiológicas em andamento. Por exemplo, considerando o aumento da população idosa e da prevalência de doenças crônico-degenerativas, é fundamental fortalecer as estratégias de prevenção - coletivas e individuais - e reorientar o sistema de saúde a partir do fortalecimento da atenção primária em uma perspectiva abrangente, assegurando o acesso aos diversos níveis de atenção, incluindo às tecnologias mais complexas. Além do fortalecimento da atenção primária e da regionalização em saúde, com conformação de redes de atenção, é importante ampliar políticas específicas voltadas para o enfrentamento de questões relevantes como a atenção materno-infantil e a atenção à saúde mental - que ainda não estão bem equacionadas no conjunto do país.

De forma associada, existem desafios importantes relativos à formação de profissionais e à gestão do trabalho em saúde para que se viabilizem as mudanças necessárias no modelo de atenção. Isso requer a aproximação entre as áreas de Saúde e da Educação - particularmente com as universidades - e a expansão das estratégias de reformulação dos currículos e de educação permanente, representando uma atribuição estratégica da esfera federal, em parceria com estados e municípios. Ainda que iniciativas importantes nesse sentido tenham sido adotadas na última década, há um longo caminho a percorrer, particularmente no que concerne à formação e à inserção dos médicos no sistema público de saúde. Isso porque não existe sistema universal de saúde nem mudança no modelo de atenção sem a incorporação de médicos qualificados e comprometidos com os serviços públicos. Além dos aspectos formativos, a adesão dos médicos ao sistema público depende da garantia de condições adequadas de vínculo, de trabalho e de remuneração, bem como é condicionada por questões mais estruturais referentes às relações público-privadas e à tradição da prática médica.

No campo de vigilância epidemiológica - atualmente compreendido na estrutura federal sob a designação mais ampla de vigilância em saúde - fazse necessária a consolidação de redes de informações eficientes que propiciem a 
intervenção para o controle não apenas das doenças infecciosas sob vigilância, como também para o enfrentamento de agravos cuja importância tem crescido em termos de morbidade e mortalidade: as doenças cardiovasculares, as neoplasias e as violências. Ou seja, mudanças no perfil de morbimortalidade da população requerem mudanças no padrão de intervenção do Estado no âmbito federal no que se refere ao campo da vigilância, já existindo esforços do Ministério da Saúde nesse sentido.

O enfrentamento dos desafios estratégicos nos dois âmbitos brevemente abordados - modelo de intervenção e campos de atuação - exige um amplo esforço da autoridade sanitária nacional e dos demais atores do setor Saúde no sentido do aumento da governabilidade sobre os rumos da política de saúde no país. Isso depende, por sua vez, questões estruturais e políticas mais amplas relativas ao modelo de desenvolvimento, à articulação entre políticas públicas e ao pacto da sociedade brasileira quanto aos níveis desejáveis de redistribuição e de igualdade social.

Em síntese, a atuação estratégica do Ministério da Saúde nas próximas duas décadas deve se orientar para: mudar o estatuto político da Saúde, afirmando-a como setor integrante de um novo modelo de desenvolvimento, centrado no bem estar social; promover a articulação virtuosa da política de saúde com as demais políticas públicas; defender a efetivação de saúde como direito de cidadania universal e fortalecer a base de apoio ao Sistema Único de Saúde na sociedade; consolidar fontes estáveis, ampliar e redirecionar o financiamento público do setor, reduzindo os subsídios ao setor privado; fortalecer a capacidade do Estado de planejamento e regulação, voltados para os interesses públicos da coletividade; reduzir as desigualdades em saúde e contribuir para a melhoria das condições sanitárias e de vida do conjunto da população brasileira. 


\section{6 | REFERÊNCIAS BIBLIOGRÁFICAS}

ALBERTO, LG; MACHADO, CV e TEIXEIRA M. O quadro de trabalhadores federais da saúde no Brasil: uma análise no contexto dos anos 2000. Physis, 21(4): 1537-1560, 2011.

ALMEIDA, MHT. O Estado no Brasil contemporâneo. In: MELO, CR; SÁEZ, MA (Orgs.). A Democracia Brasileira: balanço e perspectivas para o século 21. Belo Horizonte: Ed. UFMG, 2007. p. 17-37.

ALVES, CA; MACHADO, CV. A política do Ministério da Saúde para os hospitais federais situados no Rio de Janeiro no período de 2003 a 2006. In: MACHADO CV (org). O papel do Ministério da Saúde na política de saúde brasileira no período de 2003 a 2006. Relatório de Pesquisa FAPERJ, 2008.

ARRETCHE, M. Continuidades e descontinuidades da Federação Brasileira: de como 1988 facilitou 1995. Dados, 52(2): 377-423, 2009.

BAHIA, L. O sistema de saúde brasileiro entre normas e fatos: universalização mitigada e estratificação subsidiada. Ciência \& Saúde Coletiva, 14(3):753-762, 2009.

BANTING, K; CORBETT, S. Federalism and health care policy: an introduction. Texto para discussão apresentado no Health Policy and Federalism Workshop, realizado em São Paulo, Brasil, 15-16/ 10/ 2001.

BAPTISTA, TWF Análise das portarias ministeriais da saúde e reflexões sobre a condução nacional da política de saúde. Cad Saude Publica, 23(3): 615-626, 2007.

BARRETO, M. et al. Effect of city-wide sanitation programme on reduction in rate of childhood diarrhoea in northeast Brazil: assessment by two cohort studies. Lancet, 370: 1622-28, 2007.

BOSCHI, R.; LIMA, MRS. O Executivo e a construção do Estado no Brasil: do desmonte da era Vargas ao novo intervencionismo regulatório. In: VIANNA, L.W. (org.) A democracia e os três poderes no Brasil. Belo Horizonte: Editora UFMG; Rio de Janeiro: IUPERJ/FAPERJ, 2003, p. 195-253.

BOSCHI, R. Capacidades estatais e políticas de desenvolvimento no Brasil. In: MELO CR. E SÁEZ MA. (Orgs.) A democracia brasileira. Belo Horizonte: Editora UFMG; 2007. p.303-326.

BRASIL. MINISTÉRIO DA SAÚDE. GABINETE DO MINISTRO. Portaria GM/MS n.399 de 22 de fevereiro de 2006. Divulga o Pacto pela Saúde 2006 — Consolidação do SUS e aprova as Diretrizes Operacionais do Referido Pacto. Brasília, Diário Oficial da União 2006; 23 fev.

BRASIL. MINISTÉRIO DA SAÚDE. Mais Saúde - Direito de Todos: 2008-2011.3ª Ed. Brasília: Ministério da Saúde; 2009.

BRASIL. MINISTÉRIO DO PLANEJAMENTO, ORÇAMENTO E GESTÃO. Secretaria de Gestão. Gestão pública para um Brasil de todos: um plano de gestão para o Governo Lula / Secretaria de Gestão. Brasília: MPOG, SEGES, 2003.

BRASIL. PRESIDÊNCIA DA REPÚBLICA. Portaria GM/MS n. 2607 de 10 de dezembro de 2004. Aprova o Plano Nacional de Saúde/PNS - Um Pacto pela Saúde no Brasil. Brasília, Diário Oficial da União 2004; seção I, 238: 69.

BRASIL. PRESIDÊNCIA DA REPÚBLICA. Decreto 7336, de 19 de outubro de 2010. Aprova a estrutura regimental e o quadro demonstrativo dos cargos em comissão e das funções 
gratificadas do Ministério da Saúde e dá outras providências. Brasília, Diário Oficial da União 2010; 19 out.

DAIN, S. O financiamento público na perspectiva da política social. Economia e sociedade, n. 17: 113-140, 2001.

EVANS, P. O Estado como problema e solução. Lua Nova, n.28/29, 107-156, 1993.

FAVERET, ACSC. A vinculação constitucional de recursos para a saúde: avanços, entraves e perspectivas. Ciência \& Saúde Coletiva, 8(2): 371-378, 2003.

FIGUERAS, J. et al. Retos para los sistemas sanitarios de Latinoamérica: que puede aprenderse de la experiencia europea? Gaceta sanitaria, 16(1): 5-17, 2002.

FONSECA, C.M.O. Saúde no Governo Vargas (1930-1945): dualidade institucional de um bem público. Rio de Janeiro: Editora FIOCRUZ, 2007.

FRANCE, G. Compatibilità fra il federalismo e gli standard sanitari nazionali: una sintesi delle esperienze estere e possibili lezioni per l'Italia. In: Federalismo, regionalismo e Standard Sanitari Nazionali: quattro paesi, quattro approcci. Milano: Dott. A. Giuffrè Editore, 2001. p.169197.

GADELHA, CAG. et al. Saúde e Desenvolvimento: uma perspectiva territorial. In: VIANA, ALA; IBAÑEZ, N; ELIAS PR. (Org.). Saúde, desenvolvimento e território. 1a ed. São Paulo: HUCITEC, 2009. p. 97-123.

HAMILTON, W; FONSECA, C. Política, atores e interesses no processo de mudança institucional: a criação do Ministério da Saúde em 1953. Hist Cienc Saude Manguinhos 10(3): 791-825, 2003.

LEVCOVITZ, E.; LIMA, LD; MACHADO, CV. Política de saúde nos anos 90: relações intergovernamentais e papel das normas operacionais básicas. Ciência e Saúde Coletiva, 6(2): 269-291, 2001.

LIMA, LD. Federalismo, Relações Fiscais e Financiamento do Sistema Único de Saúde: a distribuição de receitas vinculadas à saúde nos orçamentos municipais e estaduais. Rio de Janeiro: Editora do Museu da República, 2007.

LIMA, et al. Descentralização e regionalização: dinâmica e condicionantes da implantação do Pacto pela Saúde no Brasil. Ciência e Saúde Coletiva, 2012 (no prelo). Disponível em: http:// www.cienciaesaudecoletiva.com.br/artigos/artigo_int.php?id_artigo=7249. Acesso em: 20 mar. 2012.

LUCCHESE, G. Globalização e regulação sanitária: os rumos da vigilância sanitária no Brasil. 2001. 245 f. Tese (Doutorado) — Escola Nacional de Saúde Pública, Fundação Oswaldo Cruz, Rio de Janeiro, 2001.

MACHADO, CV. O modelo de intervenção do Ministério da Saúde nos anos 90. Cad Saúde Pública, 23 (9): 2113-2126, 2007 a.

MACHADO, CV. Direito universal, política nacional: o papel do Ministério da Saúde na política de saúde brasileira de 1990 a 2002. Rio de Janeiro: Editora do Museu da República, 2007b.

MACHADO, CV; BAPTISTA, TWF, LIMA, LD. O planejamento nacional da política de saúde no Brasil: estratégias e instrumentos nos anos 2000. Ciênc. Saúde Coletiva, 15(5): 2367-2382, 2010. 
MACHADO, CV. O Modelo de Intervenção do Estado na Saúde: notas sobre a atuação federal. In: Machado, CV; Baptista, TWF; Lima, LD (Orgs). Políticas de Saúde no Brasil: continuidades e mudanças. Rio de Janeiro, Editora Fiocruz, 2012, p. 117-147.

MAJONE, G. Do Estado positivo ao estado regulador: causas e consequências de mudanças no modo de governança. Revista do Serviço Público, 1999, n. 1, p. 5-36.

MATTOS, PTL. A formação do Estado regulador. Novos Estudos Cebrap, 76: 139-156, 2006.

MORAES, MVE; SILVA, TF, COSTA, PV. O mito do inchaço da força de trabalho do executivo federal. Res Pública, 7 (2):1-17, 2009.

PACHECO, RS. Regulação no Brasil: desenho das agências e formas de controle. RAP, v. 40, n. 4, p. 523-543, 2006.

SALLUM Jr., B. Crise, democratização e liberalização no Brasil. In: SALLUM JR., B. (Org.). Brasil e Argentina hoje: política e economia. Bauru, SP: EDUSC, 2004. p. 47-77.

SANTOS, W.G. O ex-Leviatã Brasileiro. Rio de Janeiro: Civilização Brasileira, 2006.

SILVA JR, J.B. Epidemiologia em serviço: uma avaliação de desempenho do Sistema Nacional de Vigilância em Saúde. 2004. Tese (Doutorado) — Faculdade de Ciências Médicas, Universidade Estadual de Campinas, Campinas, 2004.

UGÁ, M.A.D; MARQUES, R.M. O financiamento do SUS: trajetória, contexto e constrangimentos. In: LIMA. N.T. et al.(orgs.) Saúde e democracia: história e perspectivas do SUS. Rio de Janeiro: Editora FIOCRUZ, 2005, p.193-233.

VIANA, ALA; LIMA, LD; OLIVEIRA, RG. Descentralização e federalismo: a política de saúde em um novo contexto - lições do caso brasileiro. Ciência e Saúde Coletiva, 7(3): 493-507, 2002.

WORLD HEALTH ORGANIZATION (WHO). The World Health Statistics 2010. Genebra: World Health Organization, 2010. 